\title{
PRESCRIPCIÓN ADQUISITIVA DE LAS SERVIDUMBRES CONTINUAS \\ DE ALGUNA CLASE. \\ RELECTURA DEL ART. 882 \\ DEL CÓDIGO CIVIL
}

\section{ACQUISITIVE PRESCRIPTION OF CONTINUOUS PREDIAL SERVITUDES OF ANY KIND. RE-INTERPRETATION OF ARTICLE 882 OF THE CIVIL CODE}

Gian Franco Rosso Elorriaga*

\section{RESUMEN}

La doctrina y la jurisprudencia, de conformidad con lo dispuesto en el art. 882 del Código Civil chileno, han sostenido tradicionalmente la imposibilidad de adquirir servidumbres discontinuas a través de prescripción adquisitiva. Este trabajo da cuenta de los problemas que esta posición ha generado así como de la confusión en que se basa desde el derecho común, recogida sin embargo en el Código Civil francés y en los demás código civiles decimonónicos que le siguieron. Asimismo, trata las interpretaciones alternativas en derecho comparado para superar la confusión y su posible aplicación en Chile, sin perjuicio de los cambios legislativos que han permitido la eliminación del error. Finalmente, para no seguir aplicando una disposición que conduce a resultados erróneos, propone una relectura del art. 882 y señala sus fundamentos.

* Doctor en Derecho y Magíster por la Università degli Studi di Roma Tor Vergata, Profesor de Derecho Civil y Derecho Romano en la Facultad de Derecho de la Universidad de los Andes. Dirección postal: Monseñor Álvaro del Portillo N 12.455, Santiago. Correo electrónico: grosso@uandes.cl. Artículo recibido el 30 de enero de 2017 y aceptado para su publicación el 6 de agosto de 2017.

La redacción de este artículo ha contado con la ayuda del Fondo Nacional de Ciencia y Tecnología de la República de Chile, en el marco del Proyecto FONDECYT Iniciación $\mathrm{N}^{\mathrm{O}}$ 11140856, titulado "El régimen jurídico de las servidumbres voluntarias: propuesta de reformulación dogmática a la luz de la funcionalidad actual de las disposiciones del código civil y de la legislación especial", en el cual el autor es investigador responsable. 
Palabras claves: Servidumbres discontinuas, Prescripción adquisitiva, artículo 882 del Código Civil

\section{Abstract}

The doctrine and jurisprudence, in accordance with the provisions of article 882 of the Chilean Civil Code, have traditionally held the impossibility of acquiring discontinuous easements through by acquisitive prescription. This work points out the problems generated by this position as well as the misunderstanding on which is based, from the common law, and afterwards included in the French civil code and in the rest of the nineteenthcentury civil codes who followed the later. Likewise, this paper analyzes the alternative interpretations existing in the comparative law and their possible application in Chile in order to overcome the misunderstanding, notwithstanding the legislative amendments that have allowed the elimination of the error. Finally, in order to avoid the application of a provision which leads to erroneous results, this work proposes a reinterpretation of the article 882 and exhibits its legal basis.

210 Keywords: Discontinuous predial servitudes, acquisitive prescription, article 882 of the Civil Code

\section{Recapitulación del estado aCtual del DeRecho nacional SEGÚN LA DOCTRINA Y LA JURISPRUDENCIA}

En nuestro país, pareciera ocioso preguntarse por la posibilidad que una persona pueda adquirir una servidumbre discontinua mediante prescripción adquisitiva, pues la cuestión se encontraría expresamente resuelta por el Código Civil en sentido negativo. Sin embargo, diversas situaciones problemáticas que tienen o pueden llegar a tener lugar en la realidad precisamente respecto de las servidumbres discontinuas, dejan a la vista que la insistencia en su improcedencia dista de ser correcta, justa y eficaz, además de no resultar conforme con la doctrina y el Derecho moderno. Para una mejor ilustración de la cuestión, procederemos a recapitular el estado actual en nuestro país de la materia, para luego tratar en el siguiente acápite las referidas situaciones.

Como es sabido, en nuestro Código Civil el art. $822^{1}$ clasifica las servidumbres en continuas y discontinuas y, el art. 824, en aparentes e ina-

${ }^{1}$ En adelante, los artículos citados sin indicación del Código al que pertenecen, corresponden al Código Civil chileno. 
parentes. La doctrina ${ }^{2}$ y la jurisprudencia ${ }^{3}$ reiteradamente han señalado que, en virtud de lo dispuesto en el art. 882, solo pueden adquirirse por prescripción adquisitiva de cinco años las continuas y aparentes.

Por el contrario, tal posibilidad se descarta para las discontinuas, sean aparentes o inaparentes, y las continuas inaparentes. El propio art. 882 expresa respecto de estas que ni siquiera es posible su adquisición a través del "goce inmemorial", entendido este a la luz del art. 690 del Code como

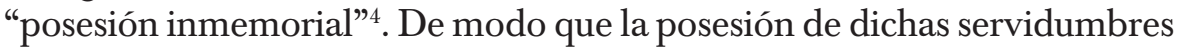
resultaría simplemente inútil ${ }^{5}$. Todo lo anterior sin perjuicio que algunos afirman que ni siquiera pueden poseerse las discontinuas y las inaparentes ${ }^{6}$.

Las posiciones precedentes, en especial esta última, se basan adicionalmente en los arts. 2499 y 917. Conforme el primero, de los actos de mera tolerancia no resulta gravamen alguno, no confieren posesión, ni dan fundamento a prescripción alguna, actos entre los cuales se comprende el dejar que el ganado del vecino transite por sus tierras eriales, los que no impondrían servidumbre de tránsito, calificada expresamente como "discontinua" por el art. 822. El segundo, no permite el ejercicio de acciones posesorias sobre las cosas que no pueden ganarse por prescripción,

${ }^{2}$ Chacón (1890), iI, pp. 581-582; Fabres (1893), p. 224, p. 139; Vera (1894), iII, p. 339; Varas (1925), p. 403; Barros (1930), p. 374, p. 471; Claro Solar (2015), tomo iv, vol.9 ${ }^{\circ} \mathrm{N}^{\mathrm{O}} 1648$, p. 293; Claro Solar (1904), p. 191; Claro Solar (2010), p. 734; Jorquera (1937), p. 49; Arellano (1949), No 67, p. 83; San Martín (1998), pp. 205 y 207; Barcia (2008), p. 196; Barcia (2010), tomo I, p. 797 y tomo III, p. 2326; SCHMidt (2009), p. 200; Vial (2014), p. 110; RuZ (2014), tomo III, p. 407.

${ }^{3}$ Véase Barrientos (2016), tomo I, pp. 1016 y 1017; De La Maza (2016), tomo I, pp. 860 y 861. Otros ejemplos: Bascuñán con Romero (1906), convertida en la doctrina modelo a seguir, es citada en distintas fuentes; Aguas del Altiplano S.A. con Dirección de Bienestar Social de la Armada (2012); Colipán Moncada, David con Bucarey Vargas, Ana María (2009); Correa Ortega, Teresa de Jesús y María Alicia con Cerda Henríquez, Edgardo (2006); Cuevas G., Patricio y otro con Sociedad Agrícola Super Ltda. (2002); Moreno Carreño, Cristóbal con Núñez Farías, René (2009); Pesse Ruiz, Juan Antonio con Molkenbürh, Silvia Ana y Berguer Dempster, Francisco (2010); Romo Pizarro, Osvaldo; González Valencia, Eugenia del Carmen con Herrera Alflatt, María Teresa (2005); Ruiz Salgado, Ninette con Kummelin Redlich, Rolf (2005); Salgado Rojas, Rosalida y otros con Rojas Zúñiga, Romerindo (2010); Sociedad Agrícola Super Limitada con Patricio Cuevas Gutiérrez y Eleazar Abarca Olivares (2002); Sucesión Gonzalo Bulnes Aldunate con Agrícola La Obra Limitada (2009); Venegas Inostroza, Olga del Carmen con Cuevas, Graciela del Carmen (2009); Villar Mareiro, Camilo y otra contra Asenjo Silva, Juan Javier y otros (2009); Yunis Ananías, Cesar con Yunis Ananías, Verónica e Hinojosa Bertiolini, Darío (2009), confirmado éste por sentencia de fecha 24 de marzo de 2010 por la CS, rol $\mathrm{N}^{\circ}$ 9335-2009.

${ }^{4}$ Varas (1925), p. 403; Claro Solar (1904), p. 191 y Claro Solar (2010), p. 734, luego de citar el art. 690, afirma simplemente que "la ley, como se ve, es la misma".

${ }^{5}$ Rodríguez (1991), p. 114.

${ }^{6}$ San Martín (1998), pp. 188-189. 
como las servidumbres inaparentes o discontinuas, lo que sería coherente con el art. 2499, pues el ejercicio de hecho no constituiría sino actos de mera tolerancia del dueño del predio y no posesión de una servidumbre.

En cuanto a los fundamentos en virtud de los cuales nuestro Código Civilnegaría la adquisición de la prescripción adquisitiva de servidumbres discontinuas e inaparentes, no se han desarrollado argumentos distintos a los expuestos por los redactores del Code, por la doctrina que le precedió o por sus comentaristas posteriores. Partiendo de la base que se está en presencia de un modo adquisitivo de servidumbres voluntarias, el ejercicio de hecho de las continuas y aparentes harían precisamente presumir la voluntad del propietario del fundo sirviente en orden a permitir el gravamen. No podría llegarse a la misma conclusión respecto del ejercicio de las discontinuas, ya que se trataría de una posesión carente de estabilidad y permanencia en el tiempo como consecuencia de su intermitencia, dado que exigen un hecho actual del hombre. Asimismo, la adquisición de servidumbres discontinuas por prescripción adquisitiva afectaría las relaciones de buena vecindad entre los propietarios. Si actos de mera tolerancia pudieran dar lugar a que los beneficiados reclamen en el futuro derechos de servidumbre, ningún dueño estaría dispuesto a conceder servicios a vecinos, en razón del temor a ver limitada su propiedad a tra212 vés de ellas, no obstante que su voluntad inicial fue solo de colaboración vecinal y no conferir derechos a terceros. En cuanto a las inaparentes, al no existir señales exteriores de su posesión, el dueño no podría tomar conocimiento de esta y, por tanto, ejercer acciones que la interrumpan. Se trataría más bien de una posesión clandestina ${ }^{7}$.

Ahora bien, desechada la adquisición mediante prescripción adquisitiva, quedaría como vía de constitución para las servidumbres discontinuas y para las servidumbres inaparentes, su establecimiento mediante título, sin perjuicio del reconocimiento expreso del dueño como título supletorio (art. 883).

En relación con la constitución a través de título, la doctrina y jurisprudencia están de acuerdo en que ella se encuentra regulada en el art. 880 inc. $1^{\circ}$, aunque ninguna referencia haga esta disposición a los títulos. Pero como lo relevante es que ella consagra como causa del establecimiento la concurrencia de la voluntad de los dueños de los predios sirviente y domi-

\footnotetext{
${ }^{7}$ Con mayor o menor extensión, estos son los argumentos fundamentales presentes y repetidos por nuestros autores. Así, CHACón (1890),tomo II, pp. 582; VERA (1894), tomo III, p. 337; Jorquera (1937), p. 49; Arellano (1949), No 67, p. 83; Pescio (1984), No 1062, p. 146; SAn Martín (1998), pp. 187 a 189 y pp. 207-208; Barrientos (2006), pp. 176-177; Vodanovic (2016), tomo II, No 1162, p. 232; Barcia (2010), tomo I, p. 797; Claro Solar (2015), tomo IV, vol. $9^{\circ}$, No 1648, p. 293 y p. 1650, pp. 294-295; PeÑaIlillo (2016), No 255, pp. 505 y 506 . Incluso, con citas expresas al Consejero de Estado Berlier y al tribuno Albisson.
} 
nante, se ha concluido tradicionalmente siguiendo a los autores franceses, que se refiere a la constitución de servidumbres mediante actos jurídicos; esto es, a través de títulos, onerosos o gratuitos ${ }^{8}$. Por regla general, estos son convenciones, pero por excepción puede tratarse de un testamento, único acto jurídico unilateral que se admitiría.

Sin embargo, nada se adquiere mediante un título constitutivo de servidumbres ${ }^{9}$. Es necesario que además opere el modo de adquirir respectivo, de acuerdo con el sistema adquisitivo general de los derechos reales que rige en nuestro país (art. 588).

Así, por ejemplo, si el título es un testamento, la constitución se producirá por sucesión por causa de muerte; si se trata de una donación, la constitución tendrá lugar cuando se realice la tradición, la que en este caso deberá realizarse a través de inscripción en el registro de hipotecas y gravámenes del Conservador de Bienes Raíces por ser las servidumbres bienes inmuebles (art. 1400) ${ }^{10}$; y si fuese una compraventa, habrá constitución cuando se celebre la tradición mediante escritura pública, según la regla general del art. 698 .

De manera que cuando el inc. $1^{\circ} \mathrm{del}$ art. 882 dice que "las servidumbres discontinuas de todas clases y las servidumbres continuas inaparentes sólo pueden adquirirse por medio de un título" y el inc. $2^{\circ}$ que "pueden adquirirse por título", las frases no pueden sino entenderse como un reenvío al art. 880 inc. $1^{\circ}$ y demás relacionados del Código Civil (v.gr.: arts. 577 inc. $2^{\circ}, 588,698,951$, etc.).

Lo dicho deja de manifiesto que la referencia a la adquisición por medio de un título no se trata más que de un error de nuestro legislador, inducido por el tenor del Code que, a diferencia del nuestro, consagró el efecto real de los contratos, motivo por el cual el solo acuerdo de voluntades sí permite la adquisición de las servidumbres.

${ }^{8}$ Claro Solar (2015), tomo iv, vol. $9^{\circ}$, No 1631 y No 1632 , p. 282; Vodanovic (2016), tomo II, No 1154, p. 227; PeÑallillo (2016), No 255, p. 502; JorQUera (1937), p. 399; SAN Martín (1998), pp. 126 y 129; Barrientos (2016), tomo i, p. 1015; GuZmán (2006), p. 185; Schmidt (2009), p. 197; Barros (1930), No 372, p. 469; Arellano (1949), No 35, p. 52; BARCIA (2008), p. 195; BARCIA (2010), tomo I, p. 793.

${ }^{9}$ Concordamos con GuZMán (2006), p. 185 que esta materia está muy mal tratada por el Código. No suele la doctrina explayarse en el punto, aunque es posible encontrar algunas referencias. Claro Solar (2015), tomo iv, vol. $9^{\circ}$, No 1633, p. 283; SAN MARTín (1998), pp. 135-136; Jorquera (1937), p. 400; Arellano (1949), No 36, p. 54; Schmidt (2009), p. 198.

${ }^{10} \mathrm{El}$ art. 1400 establece como solemnidad de la donación de bienes raíces la inscripción en el competente registro. A la disposición quedan sujetas las donaciones de servidumbres, dado que son inmuebles de acuerdo con el art. 580. Pero además, las donaciones tienen la particularidad de ser actos o contratos reales que se perfeccionan con la tradición (art. 1386), la que en el caso señalado, es solemne, pues se realiza mediante inscripción. En este sentido, GuZMán (2005), pp. 107 y 113. 
Así las cosas, en el art. 882 es posible advertir una referencia a dos elementos distintos del sistema adquisitivo chileno: a los títulos, como antecedentes jurídicos que fundamentan la operación posterior de un modo de adquirir los derechos reales; y a la prescripción, como un modo particular de adquisición de estos.

Adicionalmente, es relevante apuntar que también existe una opinio communis en cuanto a que los arts. 882 y 2512 regla $2^{\text {a }}$, habrían establecido una excepción a las reglas generales que gobiernan la prescripción adquisitiva. Conforme a ella, en materia de usucapión de servidumbres continuas y aparentes, no se distinguiría entre prescripción ordinaria y extraordinaria, existiendo una prescripción única con un término de cinco años. Ello se traduce en que este no varía, sea la posesión regular o irregular $^{11}$.

Luego, una servidumbre continua y aparente puede adquirirse en virtud de una posesión no amparada en un título o, bien, amparada en un título injusto; de mala fe; $y$, si el título fuera traslaticio de dominio, sin haberse realizado jurídicamente la tradición (arts. 702 y 708). Por lo mismo, para entrar en la posesión de una continua y aparente, bastará la prueba del animus y el corpus ${ }^{12}$. Si el título es traslaticio, este se presumirá, por cuanto la posesión de una servidumbre a ciencia y paciencia del que se obligó a entregarla hace presumir la tradición, dado que esta no debe formalmente realizarse vía inscripción del título (art. 702 inciso final).

\section{SitUACIONES PROBLEMÁTICAS RESPECTO DE LAS SERVIDUMBRES DISCONTINUAS DERIVADAS DE LA APLICACIÓN DEL DERECHO RECONOCIDO COMO VIGENTE}

Veamos enseguida, de acuerdo con lo anunciado, las distintas situaciones problemáticas que pueden tener lugar y los resultados a los cuales se llega aplicando las precedentes reglas. Para una mejor ilustración de las mismas, recurriremos a las servidumbres de acueducto y de tránsito como ejemplos, dado que son las continuas y discontinuas, respectivamente, por antonomasia.

${ }^{11}$ Claro Solar (2015), tomo iv, vol. 9, No 1649, p. 294; Peñallillo (2016), No 255, p. 506; JorQUERA (1937), p. 49; VARAS (1925), p. 408; VodANOVIC (2016), tomo II, parágrafo 1163, p. 233; San Martín (1998), p. 210; Arellano (1949), No 56, p. 77; Barcia (2010), tomo I, p. 797 y tomo III, p. 2326.

${ }^{12}$ La doctrina ha señalado que no obstante ser las servidumbres un derecho real inmueble, su posesión se rige por el estatuto jurídico de los muebles. SAN MARTín (1998), pp. 192-193. 


\section{Primera situación: ejercicio de hecho del contenido típico de una servidumbre}

Se trata de la ejecución de actos sin título alguno por parte del dueño de un predio o por personas relacionadas con él sobre otro ajeno, y que solo el propietario de un inmueble que detente una servidumbre podría realizar.

Así, por ejemplo, si el dueño de un fundo construye unilateralmente en predios que le son ajenos un canal artificial, a fin de suministrar agua al suyo, perfectamente podrá con tales actos entrar en posesión de una servidumbre de acueducto, pues tratándose de una servidumbre continua, aquella puede ser irregular ${ }^{13}$. Basta que respecto del canal existan señales exteriores que den cuenta de su presencia. La frecuencia con que pase agua por el canal no tiene importancia alguna, ya que se admiten intervalos más o menos largos (art. 822). Luego de transcurridos cinco años, la servidumbre de acueducto podrá ser adquirida por prescripción adquisitiva, conforme lo dispuesto en el art. 882 inc. $2^{\circ}$.

Diametralmente distinta es la situación respecto de una de tránsito. El caso tradicional es el del dueño, así como familiares, dependientes y otras personas vinculadas al primero que transitan a través de un fundo ajeno, para entrar o salir del propio.

Desde la perspectiva de la doctrina y la jurisprudencia tradicional revisada, el ejercicio de hecho de esta servidumbre de tránsito sería en principio una posesión irregular que no admite su adquisición mediante prescripción adquisitiva, dada su calificación de discontinua (arts. 822 y 882). Incluso más, ni siquiera se podría reconocer la existencia de posesión según algunos, porque solo estaríamos en presencia de actos de mera tolerancia del propietario del predio sirviente, dado lo dispuesto en el art. 2499. En todo caso, trátese de posesión irregular o de actos de mera tolerancia, el resultado sería el mismo, pues la distinción entre posesión regular o irregular no tendría ninguna importancia en la materia, sino solo si se está ante el ejercicio de una servidumbre continua o discontinua.

De nada sirven las señales exteriores y, por tanto, que el tránsito sea aparente, ni la mayor o menor intensidad de dichas señales, aunque el camino por el cual se transita esté, por ejemplo, asfaltado, señalizado, iluminado o con cualquier otro signo de esta magnitud, seguiría considerándosele discontinua. El mayor o menor intervalo en el ejercicio del tránsito tampoco se toma en cuenta, de modo que el paso diario, y varias veces al día, ninguna influencia tienen en la solución que reglamentaría el Código Civil. Y para qué decir del tiempo en que el tránsito pudo haberse

${ }^{13}$ Precisamente coloca como ejemplo de cuasiposesión a las servidumbres de acueducto GuZMÁN (2006), p. 208. 
ejercido, por cuanto no solo no se podrían adquirir luego del transcurso de diez años sino que ni transcurridos cien o más, dado que el art. 882 impide la adquisición aun por goce inmemorial.

La imposibilidad de adquirir servidumbres de tránsito por prescripción adquisitiva sigue hoy generando innumerables problemas, tanto en el extranjero como en Chile, y buena parte de ellos son conocidos en nuestro país a través de recursos de protección. Algunos de los fallos en este ámbito han dado lugar, incluso, a la existencia de "servidumbres de hecho" ${ }^{14}$. Asimismo, ha llevado en no pocos casos a declarar algunos servicios de paso como camino público, generándose, en la práctica, una suerte de expropiación sin indemnización para el propietario ${ }^{15}$.

Pero el actuar de los tribunales en estos excepcionales fallos no es para nada criticable. Es tan brutal la diferencia de trato como se puede apreciar que le ha dado el legislador civil a las servidumbres discontinuas frente a las continuas, que llama la atención que no tengamos más sentencias con soluciones alternativas a la regulación del Código Civil.

\section{Segunda situación: nulidad de los títulos}

216 En esta materia, corresponde tratar dos casos distintos que pueden tener lugar:

a) Nulidad del título constitutivo de la servidumbre

El título constitutivo de una servidumbre puede ser declarado nulo absoluta o relativamente. En esta eventualidad, y en virtud de la retroactividad de la nulidad, las partes vuelven al mismo estado en que se hallaban antes del otorgamiento del título, como si no hubiese existido el acto o contrato nulo (art. 1687) ${ }^{16}$. En consecuencia, cualquiera que haya sido el modo de adquirirla que hubiese operado, sus efectos desaparecen, teniéndose por no constituido el gravamen. En este sentido, la doctrina reconoce y aplica la regla "nulo el título, nula la tradición" (art. 675) ${ }^{17}$. El dueño del predio sirviente entonces estaría facultado para exigir la "restitución" del derecho real de servidumbre activa al dueño del predio dominante (art. 1687).

${ }^{14}$ Rosso (2014b), p. 37 y ss.

${ }^{15}$ Cfr. DFL No 850 de 1997 (ley de caminos), en particular, arts. 24 y 26.

${ }^{16}$ V.gr., en caso P.L., W.R. y otros con P.B., J.R. y otros (2015), se declaró la nulidad absoluta del acto de constitución de servidumbre celebrado por un mandatario cuyo mandato había expirado por la muerte del mandante.

${ }^{17}$ Peñallillo (2016), 104 bis, p. 219 y ss. 
Sin embargo, es posible que la acción de nulidad haya sido deducida después de transcurridos cinco años contados desde la fecha en que el dueño del predio dominante entró en posesión de la servidumbre; es decir, con posterioridad al plazo de prescripción adquisitiva establecido en el art. 882. Ello es perfectamente posible en la nulidad absoluta porque el término para solicitarla es de diez años. Pero también ello puede ocurrir en la rescisión, en todos aquellos casos en que el cuadrienio se comience a contar desde una fecha posterior a la entrada en posesión, como ocurre con los vicios de violencia o incapacidad (art. 1691) y en los casos especiales (v.gr. arts. 1757 y 1792-4).

Si el título declarado nulo era constitutivo de una servidumbre continua, como lo son las de acueducto, ¿ podría el titular del predio dominante alegar que ha adquirido el derecho real respectivo mediante prescripción? En otras palabras, aunque no haya operado el modo correspondiente al título debido a la declaración de nulidad de este, ¿tendría lugar al menos la usucapión?

La respuesta es positiva. Si el art. 882 admite según la doctrina tradicional una posesión irregular y, por tanto, la adquisición por prescripción adquisitiva sin título alguno, de mala fe y sin que haya tenido lugar jurídicamente la tradición si esta correspondía, no se ve razón alguna para negarle al titular de la servidumbre su adquisición por prescripción adquisitiva si transcurrieron cinco años desde que comenzó dicha posesión. Quien puede lo más con mayor razón puede lo menos. Es más, el título que adolece de un vicio de nulidad es reconocido por el Código Civil como un título injusto para poseer (art. $704 \mathrm{~N}^{\circ} 3^{18}$ ), lo que importa admitir que el detentador de un título injusto es poseedor (aunque irregular según el art. 708). Y evidentemente, la prescripción adquisitiva es la desembocadura natural de la posesión.

Pero además, debe considerarse que la posesión es un hecho, que no es concedida ni por la tradición ni por la transmisión. De manera que la falta de un requisito para que estas operen, como podría ser la nulidad del título, elimina los efectos jurídicos de ellas, pero no la entrada en posesión, que en el caso tratado significa el ejercicio del contenido típico de una servidumbre ${ }^{19}$. De ahí que, a mayor abundamiento, la tendencia

${ }^{18}$ La doctrina en general está de acuerdo que esta última disposición no distingue entre nulidad absoluta y relativa. Claro Solar (2015), tomo III, vol. $7^{\circ}, \mathrm{N}^{\circ} 828$, p. 434; VoDANOVIC (2016), tomo I, N 697, p. 390. Rodríguez (1995), p. 185, en cambio distingue entre las nulidades originarias (radical y textual), que no permitirían invocar el título para acreditar el elemento subjetivo de la posesión, y las nulidades virtuales, que por el contrario sí podrían alegarse como título de posesión.

${ }^{19}$ Se critica la expresión "la tradición da al adquirente" del art. 683, pues la posesión se adquiere por el acto unilateral de apropiación que elimina la posesión natural del tradente. Claro Solar (2015), III, 7º 728, p. 252. 
en los autores sea considerar que la prescripción adquisitiva del derecho real respectivo (en este caso una servidumbre), constituye una excepción a la obligación legal de restitución del art. $1687^{20}$.

La respuesta respecto de las servidumbres discontinuas, como lo son las de tránsito, debería ser diametralmente distinta. Si la doctrina tradicional niega su adquisición a través de prescripción adquisitiva, y aun más, la posibilidad de poseerlas, la pregunta de si puede oponerse la usucapión de ellas a la restitución derivada de la nulidad simplemente huelga. De nada serviría alegar que fue, por ejemplo, otorgada por testamento o escritura pública o, incluso, que fue inscrita. Ni tampoco que la mera tolerancia debiera descartarse en situaciones como estas. La interpretación tradicional de la doctrina y de la jurisprudencia, no permitiría llegar a conclusiones diversas.

b) Nulidad del título adquisitivo

del constituyente de la servidumbre

La hipótesis tiene como base la existencia de una servidumbre constituida por el propietario del predio sirviente en favor del titular del predio dominante mediante título (gratuito u oneroso), y adquirida en principio 218 muerte o tradición).

Pues bien, es perfectamente posible que el título (transmiticio o traslativo) por cual el dueño del predio sirviente adquirió el derecho de propiedad, sea declarado nulo, absoluta o relativamente, en virtud de la acción de nulidad deducida por un tercero ajeno a la relación de servidumbre (por ejemplo, el vendedor al cual el constituyente le compró el predio y de quien había inicialmente adquirido por tradición con la inscripción).

${ }^{20}$ Peñailillo (2016), No 104 bis, p. 222; Vial (2013), pp. 284-285; Vial (2014), p. 35; BARCia (2010), tomo II, pp. 1577-1578. En el igual sentido debe entenderse AlessANDri (2011), 1283, p. 345, quien trata expresamente como excepción a la restitución la "prescripción regida por el código de minería" respecto de las concesiones mineras, en que el plazo es de dos años para la ordinaria y de cuatro años para la extraordinaria (art. 93 del CM). Sin embargo, afirma que no podría ella ocurrir en materia civil, porque siendo nulo el título, la posesión de la cosa sería irregular, motivo por el cual el plazo para adquirirla por prescripción sería de diez años. En consecuencia, coincidirían el momento en que la nulidad absoluta se sanea y aquel en que se adquiere la cosa por prescripción. Lo mismo plantea en Alessandri (2011), No 1093, pp. 218-219. Como se puede apreciar, Arturo Alessandri reconoce la excepción, pero para que ella tenga lugar es necesario que el término de prescripción sea menor que el del saneamiento de la misma. Y esto es precisamente lo que ocurre con las servidumbres (art. 882).

Existen, sin embargo, opiniones en contrario. Así, CORRAL (2011), p. 385 y CORRAL (2016), p. 108. Pareciera de la misma opinión, aunque alude a la prescripción extintiva, BARAONA (2012), p. 135. 
Nuevamente nos encontramos con la posibilidad que la acción de nulidad haya sido deducida después de transcurridos cinco años contados desde la fecha en que el dueño del predio dominante entró en posesión de la servidumbre; es decir, con posterioridad al plazo de prescripción adquisitiva establecido en el art. 882. Ello es factible en la nulidad absoluta porque el término para solicitarla es de diez años. Pero también ello puede ocurrir en la rescisión, en todos aquellos casos citados en que el cuadrienio se comenzó a contar desde una fecha posterior a la entrada en posesión. Pero adicionalmente, se debe agregar ahora la situación en que el interesado ejerció la acción de nulidad, incluso cuando no habían transcurridos los cinco años de posesión, sin deducir en conjunto la acción reivindicatoria en contra del dueño del predio dominante (arts. 1689), la que solo se presenta después de vencido el quinquenio posesorio.

En estos casos, la nulidad del título del constituyente de la servidumbre importará como efecto el no haber jamás adquirido el dominio del predio sirviente por el modo correspondiente al título y, asimismo, en lo que nos interesa, que ningún derecho de servidumbre pudo, a su vez, transmitir o transferir el constituyente al dueño del predio dominante (art. 682). Consecuencia de ello es que la constitución fue a non domino. En otras palabras, el modo de adquirir que había operado (sucesión por causa de muerte o tradición), no produjo el efecto adquisitivo (constitutivo) de la servidumbre. Es por ello que en virtud del art. 1689, el interesado podría reivindicar el derecho real de servidumbre (arts. 891 y 1268), lo que en la práctica importa dejarlo sin efecto.

No obstante, si la servidumbre constituida era continua, como lo es la de acueducto, el titular del predio dominante podrá alegar que, habiendo quedado en calidad de poseedor del derecho (art. 883), finalmente lo adquirió mediante prescripción adquisitiva (art. 882) ${ }^{21}$. Ninguna importancia, entonces, habrá tenido que el título del constituyente haya sido declarado nulo y que el modo respectivo no haya operado. Es más, el título constitutivo sigue siendo justo y, de no haber mala fe, además de cumplida la tradición si el título era además traslaticio, la posesión es reconocida como regular.

A mayor abundamiento, la doctrina es unánime en sostener que la prescripción adquisitiva de los derechos reales es una de las excepciones al art. 1689, de manera que ella puede ser opuesta por el titular de la servidumbre activa continua al reivindicante ${ }^{22}$.

${ }^{21}$ La doctrina está de acuerdo en que un título nulo permite dejar al adquirente en posesión del derecho respectivo. Cfr. Peñailillo (2016), No 104 bis, p. 222.

${ }^{22}$ Alessandri (2011), tomo it, No 1296, p. 356; Claro Solar (2015), tomo vi, vol. $12^{\circ}$, No 1967, p. 570; Vial (2013), p. 287; BARAONA (2012), p. 137; RuZ (2014), tomo I, p. 521; Pescio (1978), tomo III, No 326, p. 242. 
Empero, una vez más, si por el contrario la servidumbre constituida era discontinua, como una de tránsito, nada de lo expresado tendrá lugar. Ni siquiera salvaría a su titular aparente la existencia de señales externas, el hecho de gozar de un justo título y de haber ejercicio la servidumbre como poseedor regular. Es más, algunos desconocen el hecho mismo de la posesión, aun cuando un justo título descarta cualquier actuación por mera tolerancia del dueño o de precario.

\section{Tercera situación: constitución de la servidumbre a non domino}

La hipótesis parte de la base, una vez más, que fue constituida una servidumbre mediante título gratuito u oneroso, pero por quien no tenía la propiedad del predio sirviente. Luego, el modo de adquirir que hubiese concurrido en la especie ningún efecto adquisitivo (constitutivo) produjo respecto de la servidumbre, pues nada podía transmitir o transferir el constituyente al dueño del predio dominante. En otras palabras, estamos en presencia de la constitución de una servidumbre a non domino ${ }^{23}$.

La cuestión se soluciona con facilidad si el constituyente o sus herederos adquieren el dominio del predio sirviente por prescripción adquisitiva ordinaria o extraordinaria, consolidándose así la servidumbre constituida, sea continua o discontinua. En tal caso, se produce un efecto retroactivo que permite entender que operó el modo de adquirir original, haya sido la tradición o la sucesión por causa de muerte (art. 682 inc. $2^{\circ}$ ). Por lo mismo, es falso en nuestro Derecho que no se pueda adquirir una servidumbre discontinua o inaparente constituida a non domino ${ }^{24}$.

En el tiempo intermedio, cabe la posibilidad que el verdadero dueño del predio sirviente reivindique el dominio de este así como también la servidumbre constituida por el dueño aparente. Ahora bien, podría

${ }^{23}$ Planiol y Ripert (1991), tomo iI, No 2951, p. 523 se quejan que los autores del Código no pensaron en la constitución de una servidumbre por un poseedor de la finca sirviente. Desde luego, los codificadores que copiaron al Code, tampoco.

${ }^{24}$ Claro Solar (2015), tomo iv, vol. $9^{\circ}, \mathrm{N}^{\mathrm{O}} 1651$, p. 295 reproduce la opinión francesa (y sus críticas) que ha sostenido que el título por el cual se deben adquirir las servidumbres discontinuas y las inaparentes, debe necesariamente ser uno emanado del dueño. Por lo tanto, si la constitución ha sido a non domino y la ley no admite otra manera de adquisición, como sería la prescripción, debe descartarse el nacimiento de la servidumbre, aunque tenga lugar una posesión inmemorial.

En Chile no es posible aplicar lo anterior pues, a diferencia de Francia, mediante el título nada se adquiere, sino que por tradición o sucesión por causa de muerte. De manera que si, por ejemplo, el tradente (constituyente) de la servidumbre se hace dueño del predio sirviente por prescripción adquisitiva, lo que opera es la adquisición de la misma por tradición, no por usucapión. 
ocurrir que la acción reivindicatoria solo la ejerza el interesado luego de transcurridos cinco años, sea sucesivamente a la reivindicación del dominio cuando la posesión del predio sirviente era regular o, bien, conjunta o sucesivamente a la reivindicación del dominio cuando la posesión del predio sirviente era irregular.

Si la servidumbre constituida era continua (además de aparente), como lo sería una de acueducto, el titular del predio dominante podrá oponer al reivindicante la prescripción adquisitiva del derecho real de servidumbre activa, dado que estuvo cinco años ejerciéndola. Si la servidumbre era discontinua, como la de tránsito, y aun cuando haya sido aparente, el titular del predio dominante ninguna prescripción podrá oponer, a pesar de que pudiera ser considerado poseedor regular por gozar de un título, encontrarse de buena fe y habérsele hecho la tradición si correspondía. Ello sin perjuicio que algunos hasta les niegan que alguna posesión hayan ejercido.

La revisión de las situaciones precedentes deja a la vista la asimétrica regulación que existe entre servidumbres continuas y discontinuas en lo que respecta a su adquisición a través de prescripción adquisitiva. Asimismo, pone de manifiesto que todas las razones copiadas por nuestra doctrina para avalar dicho resultado, son eventualmente aplicables solo a la primera de las situaciones tratadas. Ello porque la existencia de un título (nulo en el primer caso de la segunda situación y válido en el segundo caso de esta así como en la tercera situación), lleva necesariamente a descartar que los actos ejecutados por el dueño del predio dominante puedan calificarse de mera tolerancia o de precario.

Por el contrario, la segunda y tercera situación muestran a un dueño del predio dominante que goza de un título (justo o injusto); que a su favor se ha transferido o transmitido el derecho real de servidumbre respectivo; que ha poseído efectivamente (incluso hasta regularmente); y que esta posesión se ha extendido por cinco años. Sin embargo, a la luz de la doctrina tradicional recapitulada en el acápite inicial, ningún derecho real de servidumbre activa se podría adquirir si esta es discontinua. ¿ Tantas diferencias tiene en la práctica una de acueducto respecto de una de tránsito?

\section{IMPOSIBILIDAD DE ADQUIRIR LAS SERVIDUMBRES DISCONTINUAS POR PRESCRIPCIÓN ADQUISITIVA: \\ el resultado de una lamentable confusión en el Derecho Común}

Como recordamos, la distinción entre servidumbres continuas y discontinuas se encuentra consagrada en el art. 822. Ella, sin embargo, está históricamente basada en una lamentable confusión, a la cual ya nos 
hemos referido en otros trabajos ${ }^{25}$. Una cosa es la causa de las servidumbres y otra es su posesión o ejercicio, admitiendo ambas ser catalogadas de continuas y discontinuas.

En efecto, el gravamen en que consiste una servidumbre puede producirse naturalmente, caso en el cual se habla de perpetua (o natural ${ }^{26}$ ) o, bien, requerir actos del hombre para generarlo, caso en el cual la causa serán precisamente dichos actos. Así, en el caso de una servidumbre de acueducto, que es el ejemplo que el art. 822 da de continua, y en que la carga consiste en soportar el paso de las aguas, la causa de este gravamen es originalmente la ley de gravedad, ya que las aguas escurren (pasan) por el predio sirviente sin necesidad de un hecho del hombre; es la naturaleza la que las impulsa y, por tanto, su causa es permanente ${ }^{27}$. Lo mismo ocurre con el gravamen sobre una propiedad de soportar las aguas lluvias que escurren desde el edificio del vecino ${ }^{28}$, o de soportar en las vigas propias la estructura de una casa ajena, las cuales también son servidumbres perpetuas, pues la carga tiene una causa natural, debido a que se produce permanentemente sin la intervención del hombre. Este último solo participó en la construcción de las estructuras, pero, a continuación, el gravamen es causado sin su actividad.

Se advierte sí que, si se atiende a la efectividad del gravamen, en los dos primeros ejemplos, las servidumbres podrían ser calificadas de discontinuas, en cuanto el paso del agua es a veces intermitente y las aguas lluvias

${ }^{25}$ Rosso (2016), p. 357 y ss.; Rosso (2013), p. 949 y ss.

${ }^{26}$ No debe confundirse "servidumbre con causa natural" de las denominadas "servidumbre naturales", contempladas en los arts. 831 y 833. El criterio de distinción de estas últimas es la fuente de constitución o nacimiento de las mismas: "la natural situación de los lugares", a diferencia de las que se constituyen por imposición de la ley o por un hecho del hombre. Deja de manifiesto que se trata de servidumbres diversas el art. 879 que no reconoce el carácter de legal a la servidumbre de aguas lluvias, admitiendo que puede constituirse una voluntaria. De constituirse, la servidumbre de aguas lluvias nacerá por un hecho del hombre, pero la causa del gravamen será natural o perpetua, pues la carga al propietario del predio sirviente la producirá la naturaleza, sin la exigencia de una intervención del hombre.

Sobre la clasificación entre servidumbres naturales, legales y voluntarias, precisamos que su origen, la base del sistema al que pertenece y de su tratamiento en Chile, fue el Código de Napoleón. Este introdujo dichas categorías, no obstante estas no tenían ningún arraigo ni desarrollo histórico. Aparece en el Répertoire universal et raisonné de jurisprudence en 1783, justo antes de la dictación del Code. No habiendo madurado, "se adoptó una nomenclatura confusa y una sistemática deficiente”: Amunátegui (2013a), p. 33 y Amunátegui (2013b), p. 614.

${ }^{27} \mathrm{La}$ idea se encuentra contenida en el art. $79^{\circ}$ del Código de Aguas, al señalar: "La servidumbre comprende el derecho de llevar el acueducto por un rumbo que permita el libre descenso de las aguas". Se trata de una condición esencial para que opere la causa de la carga.

${ }^{28}$ Esta servidumbre debe imponerse en nuestra legislación voluntariamente conforme el art. 879 . 
son siempre intermitentes (no llueve ininterrumpidamente), mientras que en el tercero de los ejemplos, sería continua, en cuanto la viga soporta sin interrupciones de ningún tipo la estructura ajena.

Distinto es el gravamen consistente en que un predio sirviente deba soportar el paso de agua a través de un canal de regadío en él establecido, cuando la causa de dicho paso sea la extracción del agua desde un pozo manualmente o por un mecanismo automático dispuesto por el hombre. Aun cuando la extracción de agua sea ininterrumpida (como puede ocurrir en el segundo caso) o, bien, solo a ciertas horas del día, el gravamen lo causan hechos del hombre (acciones destinadas a la extracción del agua y vertimiento en el canal), de modo que su causa no es perpetua o natural. Más aún si total o parcialmente el recorrido del agua debe luchar contra la gravedad (el agua debe subir en distintos tramos), requiriendo del impulso que le dé la presión generada por la intervención del hombre, toda vez que el agua no pasará y el gravamen de soportar el paso no se producirá.

Cualquiera sea la causa del gravamen, la naturaleza o el hecho del hombre, lo cierto es que ella necesariamente es invariable o inmutable respecto a cada servidumbre, por lo que la continuidad o discontinuidad de la causa será a su vez invariable o inmutable. Esta regla ha sido reconocida en Chile ${ }^{29}$.

En cambio, la posesión o ejercicio de una servidumbre, nada tiene que ver con la causa del gravamen (perpetua o un hecho del hombre). Al respecto debe considerarse que la posesión de derechos reales (cuasiposesión) consiste en el ejercicio de ciertas actividades materiales sobre la cosa corporal respectiva, coincidentes con el contenido típico de un derecho real $^{30}$. Es decir, consiste en el aprovechamiento o goce de hecho de una cosa, bajo la apariencia de estar ejerciéndose un derecho. De modo que "poseer una servidumbre significa ejercitarla. Difícilmente puede descartarse este concepto" 31.

El concepto de 'posesión' no es alterado cuando se trata de un derecho real de servidumbre, incluso de las llamadas discontinuas, puesto que su adquisición por usucapión "se fundamenta en el efectivo aprovechamiento de lo que será el contenido del derecho real", esto es, en "beneficiarse del mismo estado de hecho en que consistirá una vez consolidada" ${ }^{32}$. Se comprenderá que ello es tan aplicable a las llamadas servidumbres continuas como a las discontinuas.

\footnotetext{
${ }^{29}$ Fundado en los autores franceses, Claro Solar (1904), p. 188; Claro Solar (2010), p. 731.

${ }^{30}$ Guzmán (2006), pp. 162 y 164. En el mismo sentido, Claro Solar (2015), tomo IV, vol. $9^{\circ}, \mathrm{N}^{\mathrm{O}} 1652$, p. 296.

${ }^{31}$ Biondi (2002), p. 1164.

${ }^{32}$ Rebolledo (2013), tomo i, p. 227.
} 
Este ejercicio o posesión puede ser continuo o discontinuo a su vez. Así, se tratará de una posesión continua cuando tengan lugar

“actos de ejercicio lo suficientemente próximos para que los intervalos que los separan correspondan a los que median entre los actos de ejercicio normal de un derecho, y que no puedan ser tomados como interrupción de la posesión"33.

Si los intervalos no corresponden a un ejercicio normal, la posesión será discontinua. De modo que si se transita regularmente por un camino trazado en suelo ajeno hacia un predio propio, hay una posesión continua. En cambio, si ello es más bien esporádico y ocasional, se trata de un ejercicio discontinuo. Ello porque el criterio de distinción entre posesión continua o discontinua no es el ejercicio ininterrumpido de actos materiales posesorios, sino la disposición permanente de la cosa al servicio; esto es, la posibilidad o poder de llevar a cabo dichos actos.

A pesar de lo expresado, y como se adelantó, la causa del gravamen, continua o discontinua, y la posesión del gravamen, continua o discontinua, terminaron confundidas. Esta confusión tuvo principalmente su origen en la regula infallibillis de Bartolo, destinada a fijar cuándo se puede y cuándo 224 no se puede adquirir una servidumbre por usucapión ${ }^{34}$.

El problema fue detonado por la circunstancia que glosadores y comentaristas se enfrentaron con pasajes de juristas romanos que en apariencia resultaban contradictorios. Así, las servidumbres rústicas o urbanas no se podían adquirir por usucapión según D.8.1.14 pr; mas, conforme D.41.3.10.1, ello sí era factible respecto de las urbanas. Asimismo, tampoco se descartaban necesariamente a todas las rústicas, pues una de ellas, la aquea ductus, podía adquirirse por prescripción adquisitiva a la luz de D.8.5.10.

Los glosadores, sin atender a que las contradicciones obedecían al origen en distintas épocas de los textos tenidos a la vista ${ }^{35}$, a fin de armo-

\footnotetext{
${ }^{33}$ LACRUZ (1954), p. 560.

${ }^{34}$ Coviello (1890), pp. 163 -164; Biondi (1969), No 74, pp. 211 y 212; Barasi (1947), p. 196 y ss.; Messineo (1949), No 31, p. 65; Lacruz (1954), p. 525 y ss.; Cerdeira (2000), p. 36 y ss.

${ }^{35}$ Originalmente las servidumbres podían adquirirse por usucapión (dado que no existía aún la noción de un derecho o gravamen distinto al inmueble al que materialmente pertenecían); luego, en Derecho clásico, ello no era posible por orden de la lex scribonia (I a.C.) según D.41.3.4.28 (29), en razón de que las cosas incorporales no eran susceptibles de posesión; y, finalmente, en época Justinianea, todas las servidumbres podían adquirirse mediante longi temporis praescriptio (C.7.33.12.4; C.3.24.2). LÁZARO (2002), p. 62 y ss; D’OrS (2008), No 195 , pp. 272-273; GuZMán (2013), tomo I, pp. 699-700; Biondi (2002), p. 399; Burdese (1993), pp. 355-356.
} 
nizarlos y superar la cuestión, desarrollaron la idea que podían adquirirse por usucapión las servidumbres que tuviesen una "causa perpetua". Esa última noción la toman principalmente de D.8.2.28 (en relación con D.43.22.1.4), donde Paulo, a propósito de un agujero en la parte inferior de la pared de una habitación, comenta que se decidió no considerarlo un conducto que recibe y vierte aguas sobre tejados ajenos (canalón), motivo por el cual no podía ser adquirido por el tiempo. Agrega que la decisión es correcta, porque si el agua no cae del cielo, sino que se introduce "con la mano", no tiene el servicio (que prestan los inmuebles que reciben el agua) una causa perpetua; pues si cayera del cielo, aun cuando no fuere asiduamente, tendría una causa natural, dado que caería perpetuamente. En otras palabras, el por qué sí podía adquirirse en algunos casos por usucapión y el por qué no podía adquirirse en otros, estaba determinado por la concurrencia o no de "causa perpetua" 36 .

Bartolo recepciona dicho criterio, procurando contestar la pregunta siguiente: ¿̇cuándo concurre y cuándo no concurre una causa perpetua? La respuesta la encuentra en la noción de "continuidad", de modo que es perpetua una causa cuando ella es continua; no es perpetua cuando es discontinua. Entonces, lo que corresponde determinar es en qué casos es continua y en qué casos es discontinua. Para ello acudió a su regula infallibillis: es continua (por tanto perpetua) si no requiere de un hecho del hombre; en caso contrario, es discontinua (no perpetua) ${ }^{37}$.

El resultado práctico del razonamiento descrito, y que era lo finalmente perseguido, fue: las servidumbres continuas ${ }^{38}$, porque tiene causa perpetua, pueden adquirirse por prescripción, lo que se traduce implícitamente en el entendimiento que esa continuidad es de la posesión, que es el requisito

${ }^{36}$ Cabe advertir que "causa perpetua" en sí misma ha constituido uno de los problemas conceptuales más serios a que se ha enfrentado la romanística en esta materia, por cuanto en el mismo pasaje citado, Paulo afirma a continuación que "omnes autem servitutes praediorum perpetuas causas habere debent" ("pero todas las servidumbres de los predios deben tener causas perpetuas”). Véase al respecto el clásico trabajo de Perozzi (1893), p. 2 y ss.

${ }^{37}$ Bartolo expresa en su comentario: "Pero cómo saber si las servidumbres tienen una causa continua o no, yo daré una regla infalible. $\mathrm{Si}$, en efecto, es necesaria para el uso de las servidumbres de un hecho del hombre, se dice que nunca tiene una causa continua, ya que una persona no puede trabajar de forma continua. Si por el contrario no requiere hecho del hombre, se dice que tiene entonces una causa continua, o cuasi continua. Y parece que es por esto que las servidumbres de vía y de paso no tienen causa continua, ya que no puede siempre un hombre ir, mientras que la servidumbre de acueducto puede tener causa continua, pues el agua siempre fluye, o puede fluir, pero si requiere de un hecho del hombre, como por ejemplo podría ser necesario que el agua sea extraída de alguna fuente o de una zanja, y vertida en algún canal, entonces no tendría causa continua”. BARTHOLUS (1996), tomo IV, p. 127 (Rúbrica, Si quam, C.3.34.2).

${ }^{38}$ Habría hablado de "servidumbre continua" Caepolla. Biondi (2002), p. 399. 
previo y esencial para que tenga lugar este modo de adquirir; en cambio, las servidumbres discontinuas, porque no tienen causa perpetua, no pueden adquirirse por prescripción, debiendo entenderse que es porque la posesión resulta discontinua. Es decir,

"al negar que pueda ser continua la posesión de aquellas servidumbres cuya utilización requiere el hecho del hombre, se confunde la continuidad de la posesión con la continuidad del ejercicio"39.

Todo ello explica que una servidumbre de acueducto haya sido considerada habitualmente con causa perpetua, por ser continua (el agua fluye sola, sin la acción del hombre, y sin perjuicio que pueda dejar de fluir en ciertos momentos), pudiendo ser adquirida por prescripción adquisitiva; y por el contrario, una de paso se le haya considerado sin causa perpetua dado que es discontinua (porque no puede el hombre estar pasando ininterrumpidamente), no pudiendo ser ganada por usucapión.

\section{RECEPCIÓN DE LA CONFUSIÓN EN EL CODE Y DEMÁS CÓDIGOS DECIMONÓNICOS}

Si bien se trataba de una clasificación no pacífica en doctrina, la distinción entre servidumbres continuas y discontinuas era aceptada en la práctica y por los tribunales, siendo acogida por las codificaciones decimonónicas ${ }^{40}$. Entre ellas, el caso más relevante, sin dudas, fue el Código Civilfrancés, el cual recepcionó en su art. 688, a pesar de las diferencias entre los jurisconsultos de la época ${ }^{41}$, tanto la distinción como el criterio de distinción que conocemos: necesidad o no de un hecho actual del hombre para su ejercicio ${ }^{42}$. Por su parte, los arts. 690 y 691 del Code, sobre la base de dicha clasificación, completaron el sistema desarrollado a partir de la regula infallibillis de

${ }^{39}$ LACRUZ (1954), p. 526.

${ }^{40}$ Coviello (1890), p. 174.

${ }^{41}$ Juan Albisson reconoce durante la tramitación del Code que existía disputa sobre el criterio de esta clasificación, señalando que la distinción entre servidumbres continuas y discontinuas, junto con las aparentes e inaparentes, era esencial para la adquisición o pérdida de derechos que ellas producen, que sin razón son rechazadas por célebres juristas; y que confundida por subdivisiones y detalles tan minuciosos como inútiles, era menester que la ley aclarara. FenET (1827), tomo XI, p. 325.

${ }^{42}$ Art. 688: "Les servitudes sont ou continues, ou discontinues./Les servitudes continues sont celles dont l'usage est ou peut être continuel sans avoir besoin du fait actuel de l'homme: tels sont les conduites d'eau, les égouts, les vues et autres de cette espèce./ Les servitudes discontinues sont celles qui ont besoin du fait actuel de l'homme pour être exercées: tels sont les droits de passage, puisage, pacage et autres semblables". 
Bartolo $^{43}$, estableciendo la imposibilidad de adquirir servidumbres discontinuas, aparentes o no aparentes, mediante usucapión; desechando la posesión denominada inmemorial ${ }^{44}$. La recepción gala, como sabemos, fue el principal vehículo de expansión de la confusión al resto de los códigos del siglo XIX.

La solución francesa concretamente fue explicada en su momento como una medida transaccional, entre las regiones que se regían por el Derecho consuetudinario y que negaban la adquisición de toda servidumbre por prescripción, incluso inmemorial (v.gr., las Costumbres de París, art. 186) y las otras en que prevalecía el Derecho Romano, admitiendo la prescripción cumplidos treinta años de posesión, si eran ostensibles, y aun la prescripción inmemorial si no lo eran ${ }^{45}$. Empero, la razón de fondo era la confusión entre posesión continua y servidumbre continua. En este sentido señalan Marcel Planiol y Georges Ripert que ya Bertrand D'Argentré había expuesto en el siglo XVI que la prescripción de las servidumbres continuas era posible porque resultaba de la posesión natural y permanente de las obras hechas para el ejercicio de la misma, mientras las discontinuas eran imprescriptibles conforme al Derecho Romano ${ }^{46}$.

Advirtiéndose ya a la época de la codificación francesa lo erróneo que era confundir la posesión discontinua con las servidumbres discontinuas, los autores habían comenzado a colocar su acento en un argumento distinto para explicar el contenido de los arts. 690 y 691 del Code: la circunstancia que el ejercicio de hecho de servidumbres, esto es, sin un título que lo avale, importa en realidad una posesión viciada de precario. Por lo mismo, la aceptación del dueño del predio sirviente de tales actos se debe solamente a su mera tolerancia, basada en las buenas relaciones vecinales. De modo que si alguna prescripción adquisitiva se permitiera, los dueños de los predios dejarían de prestar servicios a los propietarios de los fundos vecinos, por temor a que los mismos terminaran transformados en servidumbres. El argumento tuvo su respaldo legal en el art. 2232 (hoy art. 2262), según el cual no pueden fundamentarse ni la posesión ni la prescripción en actos

${ }^{43}$ Biondi (2002), p. 399.

${ }^{44}$ Art. 690: "Les servitudes continues et apparentes s'acquièrent par titre, ou par la possession de trente ans". Art. 691: "Les servitudes continues non apparentes, et les servitudes discontinues apparentes ou non apparentes, ne peuvent s'établir que par titres./ La possession même immémoriale ne suffit pas pour les établir, sans cependant qu'on puisse attaquer aujourd'hui les servitudes de cette nature déjà acquises par la possession, dans les pays où elles pouvaient s'acquérir de cette manière".

${ }^{45}$ Fenet (1827), tomo Xi, pp. 325-326; Planiol y Ripert (1996), p. 542; Terré et Simler (2014), 895, p. 792.

${ }^{46}$ Planiol y Ripert (1996), p. 542; Planiol y Ripert (1991), tomo it, 2949, p. 519. 
de simple tolerancia ${ }^{47}$. Este famoso argumento, como recordásemos en el acápite I, es profusamente replicado por los doctrinarios chilenos.

No obstante lo expresado, ni siquiera la recepción francesa significó una aceptación de la confusión entre servidumbre continua y posesión continua y, consecuencialmente, la posibilidad de adquirir esta clase por usucapión. Tampoco la argumentación basada en la mera tolerancia convenció a la doctrina. Muy por el contrario, esta hasta hoy critica los supuestos fundamentos de las disposiciones así como el contenido de los arts. 690 y $691^{48}$. Particularmente se objeta que se trate de darle el carácter de presunción absoluta a la mera tolerancia, en circunstancias que en muchos casos esta no existe. Las palabras de Marcel Planiol y Georges Ripert son más que elocuentes:

"el sistema admitido por el Código se presta a las más vivas críticas, siendo casi imposible hallar un fundamento racional a la doble condición de apariencia y continuidad" 49 .

Frente a ello, tanto los autores como la jurisprudencia han recurrido a los más variados subterfugios a fin de eludir las erróneas disposiciones. Así, dado que la ley impide la adquisición de la servidumbre discontinua de paso por prescripción, se ha tratado de ampliar la noción de las continuas, generándose una jurisprudencia vacilante, con la consecuencial inseguridad jurídica que ello conlleva; se ha admitido la adquisición de la propiedad del terreno mismo sobre el cual se ejerce el tránsito; se ha permitido la adquisición de la copropiedad o, bien, de un derecho de uso en vez de las respectivas servidumbres; se relajaron los requisitos de los medios probatorios a fin de facilitar la prueba de las mismas, aceptándose simples indicios o declaraciones tácitas como suficiente título; se expandió lo más posible la noción de título; se ha sustituido el concepto de servidumbre por el de un derecho sui generis distinto (v.gr., el paso de los habitantes de un lugar por un camino privado es un derecho diferente o, bien, es un camino público o, bien, el paso no es una servidumbre sino un derecho de explotación agrícola $)^{50}$. En general, se ha mitigado el

${ }^{47}$ Planiol y Ripert (1996), p. 543; Terré et Simler (2014), No 895, p. 792.

${ }^{48}$ Planiol y Ripert (1991), tomo it, 2949, pp. 520-521; Planiol y Ripert (1996), p. 543; Terré et Simler (2014), No 895, p. 792; Josserand (1952), tomo i, vol. 3, No 1992 , p. 469; Jourdain (1995), No 152-1, pp. 209-210; Mazeaud y Chabas (1994), tomo il, vol. $12, \mathrm{~N}^{\mathrm{O}} 1713$, pp. 432-433.

${ }^{49}$ Planiol y Ripert (1946), vol. 3, No 956, p. 797. En el mismo sentido, Josserand (1952), tomo I, vol. 3, $\mathrm{N}^{\mathrm{o}} 1992$, p. 469.

${ }^{50}$ De Page (1942), vol. vi, No 624, pp. 514-515; Berguel, Bruschi y Cimamonti (2000), p. 342, pp. 343-344; Jourdain (1995), No 151-153, p. 209 y ss.; Mazeaud y Chabas (1994), 
rigor de la imposibilidad de adquirir por prescripción las servidumbres discontinuas, apelando a criterios que permitan entender como continuas aquellas que según el Code serían discontinuas ${ }^{51}$.

Habiéndose transformado el Código Civil francés en el gran modelo del proceso codificatorio decimonónico, la distinción entre servidumbres continuas y discontinuas, la confusión con la posesión continua y discontinua y la imposibilidad de adquirir por prescripción adquisitiva estas últimas, se transmitió a buena parte de los códigos de la época. Así, se reprodujeron los arts. 690 y 691 del Code entre los códigos europeos que mayor influencia tuvieron en América: en el Código Civilitaliano de 1865, en los arts. 629 y 630; y en el español de 1889, en sus arts. 537 y 539.

Particular sí es la situación de España, pues, siguiendo el proyecto de Florencio García Goyena, eliminó la continuidad para la destinación del padre de familia (art. 541 del Código Civil español) manteniéndola, sin embargo, para la usucapión. Esta solución en todo caso no significó más que seguir con la tradición, a la luz de los que disponían Las Partidas ${ }^{52}$. Aun así fue erróneo mantener la continuidad en la prescripción adquisitiva, y más grave el equívoco en la codificación española, por cuanto el Código fue aprobado en el año 1889, cuando ya la doctrina y jurisprudencia francesa habían reconocido la confusión y el error de los arts. 690 y 691 del Código Civil francés ${ }^{53}$. Y peor aún, la fórmula española fue seguida por varios códigos latinoamericanos que utilizaron al Código español como modelo ${ }^{54}$, habiendo tenido aún más tiempo y oportunidades para enmendar el rumbo.

Ahora bien, así como otros códigos civiles reprodujeron las disposiciones francesas, los fundamentos dados por los autores para ello se centraron

tomo II, vol. 12, No 1719, pp. 435-437; Josserand, tomo I, vol. 3, No 1993, pp. 469-470; CoLIN y CApitant (1952), pp. 536-537; Planiol y Ripert (1991), tomo II, No 2950, pp. 521-522.

${ }^{51}$ Jourdain (1995), No 146, pp. 204-205; LaURent (2004), p. 4, en su cargo de conseiller référendaire à la Cour de cassation.

${ }^{52}$ Cfr. Partida 3.31.15.

${ }^{53}$ Se queja Cerdeira (2000), p. 28, de que lo recogido "ibien podría haber sido esa corriente doctrinal y de la jurisprudencia francesa opuestas a los art. 690 y 691 del Code!”. La misma crítica en CeRdEIRA (2015), pp. 425-426. Debe señalarse que desde luego parte de la doctrina está muy cómoda con la restricción a la adquisición de servidumbres por prescripción adquisitiva. LASARTE (2007), pp. 381-382, es partidario de restringir la adquisición por usucapión de los fundos, pero cambiando los criticados argumentos por la simple libertad de predios. El problema es que, o se restringe para todas, o se amplía para todas, pero no para unas y otras no, solo en razón de una confusión conceptual. En Chile, este simple argumento de la libertad de los predios no podría prosperar, en razón de la función social de la propiedad, consagrada en el art. 19 N 24 de la CPR. Recuerda de su aplicación en materia de servidumbres, SCHмidt (2009), p. 196.

${ }^{54}$ Por ejemplo, 1114 del CC.DF de Mex. y art. 521 del CC. de Pan. 
en el argumento ya referido de que los actos a título de precario no pueden dar lugar a posesión ni consecuencialmente a prescripción adquisitiva. Sin embargo, como ya señalamos, esta explicación solo tiene, en verdad, relación con la primera situación vista en el acápite iI. No así en cambio con las situaciones en que ha existido un título en favor del predio dominante que fue, anulado o, bien, simplemente a non domino. De modo que para los estudios del Derecho, que ya consideraban que la imprescriptibilidad de las servidumbres discontinuas era en sí misma errónea, su extensión a la segunda y tercera situación tratadas en el acápite II, sencillamente comenzó a ser mirada como una injusticia de proporciones.

Esto motivó el desarrollo por parte de la doctrina de interpretaciones de las disposiciones del Código Civil que permitieran al menos excluir a los poseedores regulares de la prohibición. Los resultados han tenido mayor o menor éxito según los textos concretos de cada Código Civil, los cuales presentan algunas diferencias en la materia. Sobre el particular, nos referimos en el acápite siguiente.

\section{LA SUPERACIÓN DE LA CONFUSIÓN A TRAVÉS DE LAS REINTERPRETACIONES Y RECODIFICACIONES CIVILES}

Para el mejor entendimiento de estas interpretaciones, debe tenerse presente que Justiniano fusionó la usucapio original del Derecho Civil con la temporis praescriptio desarrollada en provincias. Respecto de los muebles, estableció la necesidad de una posesión regular de tres años para usucapirlos. Respecto de los inmuebles, distinguió por una parte la adquisición mediante longi temporis praescriptio, que exigía justa causa, buena fe y una posesión de diez años entre presentes y veinte años entre ausentes ${ }^{55}$, que hoy llamamos ordinaria. Y por otra, una longissimi temporis praescriptio, que exigía buena fe y una posesión por regla general de treinta años, pero sin requerir justo título, que hoy conocemos como extraordinaria.

El Código Civil francés reguló la prescripción adquisitiva de diez y veinte años en el art. 2265 y la prescripción de treinta años en el art. 2262 (hoy refundidos en el art. $2272^{56}$ ). Luego, una parte minoritaria de la doctrina francesa sostuvo que el art. 690 se refiere exclusivamente a la prescripción extraordinaria de treinta años (la norma dice "possession de trente ans"). Luego, cuando el art. 691 señala que solo se pueden adquirir

${ }^{55}$ La ausencia o presencia del dueño contra el cual se prescribe en la provincia donde se ubica el inmueble.

${ }^{56}$ Ley $\mathrm{N}^{\circ} 2008-561$ de 17 de junio de 2008 modificó las disposiciones del Code en materia de prescripción. 
mediante prescripción adquisitiva las servidumbres continuas, la prescripción a la que alude esta disposición sería precisamente la señalada en el artículo anterior: la de treinta años. En otras palabras, el Code limitó la adquisición de las servidumbres por prescripción cuando falta un título y la buena fe, pero nada dijo respecto de la prescripción cuando sí concurre un título y buena fe.

Dado que el Derecho Romano admitía la usucapión de las servidumbres transcurridos diez o veinte años, no es seguro que los redactores del Código hayan querido negarle su efecto ordinario a la buena fe. Por ser de Derecho Común la usucapión decenal y veintenar, tan solo podría excluirla una expresa disposición en contrario ${ }^{57}$, lo que en el caso no ocurre. Y precisamente, frente a la mayoría que excluye también la prescripción de diez y veinte años al caso del que ha tratado con un non domino en virtud del tenor del art. 690, Louis Josserand afirma:

"el argumento es caprichoso y hasta un tanto pueril; es el ejemplo típico del mal argumento en contrario. De la afirmación de la una no se podría concluir la condenación de la otra, tanto más cuanto que responden a preocupaciones muy diferentes" ${ }^{\prime 5}$.

En síntesis, según la doctrina referida, el art. 690 del Code solo excluyó a las servidumbres discontinuas y a las inaparentes de la adquisición por prescripción adquisitiva extraordinaria. Por el contrario, ellas pueden adquirirse por prescripción adquisitiva ordinaria conforme las reglas generales (las que incluían sí la imposibilidad de cualquier adquisición si el título era declarado nulo por la forma, según el art. 2267, actualmente art. 2273).

Por su parte, el Código Civil italiano de 1865, si bien siguió los arts. 2262 y 2265 en los arts. 2135 y 2137 respectivamente, introdujo algunas modificaciones relevantes frente al modelo francés. Entre ellas, descartó la prescripción de veinte años y, por consiguiente, la distinción entre presentes y ausentes, fijando un plazo único de prescripción de diez años. Pero la novedad más relevante fue la inserción en el texto del art. 2137 de la expresión "o un diritto reale sopra un immobile". De manera que la disposición no solo admitió la adquisición de inmuebles mediante usucapión por una posesión continua de diez años sino, además, la de cualquier derecho real, concurriendo buena fe y título en los términos indicados. Evidentemente, entre los derechos reales debían considerarse las servidumbres.

${ }^{57}$ Mazeaud y Chabas (1994), tomo II, vol. 12, No 1720 , p. 437.

${ }^{58}$ Josserand (1952), tomo I, vol. 3, No 1996, p. 472. 
Lo anterior facilitó la tarea a la doctrina italiana toda vez que, efectivamente pudo sostener, al igual que en Francia, que de acuerdo con el tenor de los arts. 629 y 630 (arts. 690 y 691 del Code), la adquisición de las servidumbres discontinuas solo estaba excluida respecto de la prescripción adquisitiva extraordinaria o irregular de treinta años. Pero a diferencia de la normativa francesa, esta posición era ratificada por el art. 2137, pues este permitía en forma expresa la adquisición a través de la prescripción ordinaria o regular de todo derecho real, incluyendo a las servidumbres, sin distinguir entre continuas y discontinuas.

En otras palabras, la regla general en Italia era que se podían adquirir por prescripción adquisitiva todas las servidumbres; mientras que la excepción solo era aplicable a un tipo de prescripción: la extraordinaria de 30 años para servidumbres discontinuas y las servidumbres inaparentes. Luego, los poseedores de buena fe y que gozaran de un título transcrito, no tenían impedimentos para alegar la adquisición del respectivo derecho real por usucapión (salvo que el título, como en Francia, fuera declarado nulo por la forma) ${ }^{59}$.

Por último, el Código Civil español siguió el mismo esquema que el francés, pero también con cambios en la redacción. Como adelantamos, los arts. 537 y 539 corresponden a los arts. 690 y 691 del Code, mientras que los arts. 1957 y 1959 con los arts. 2262 y 2265 del Código francés. 232 Entre las alteraciones, el art. 537 finaliza diciendo "por la prescripción de veinte años" (en vez de treinta); los arts. 1957 y 1959 incluyeron como el italiano "y demás derechos reales", expresión que comprende a las servidumbres; y el art. 1959 agregó en la parte final "salvo la excepción determinada en el artículo 539".

Luego la doctrina española, a partir de este contexto y en particular sobre la base del brillante trabajo de José Luis Lacruz sobre la "Usucapión de las servidumbres discontinuas y no aparentes" en que siguió en la materia a los autores italianos ${ }^{60}$, ha llegar a concluir en síntesis: primero, que, aunque las normas generales sobre prescripción aludan genéricamente a los derechos reales, la última frase del art. 1959 excluye toda posibilidad de adquirir servidumbres discontinuas a través de la prescripción adquisitiva extraordinaria de treinta años; segundo, que a diferencia del art. 1959, el art. 1957 no contiene por el contrario ninguna excepción, lo que significa que la adquisición de derechos reales sobre inmuebles, incluyendo las servidumbres discontinuas, está permitida a través de la prescripción ordinaria (en definitiva, se aplica el adagio "lo

${ }^{59}$ Coviello (1890), p. 196 y ss.; SACChi (1902), tomo i, No 97, p. 641; Butera (1923), $\mathrm{N}^{\mathrm{o}} 195$, pp. 385-386. Un resumen del desarrollo de la doctrina italiana puede verse en Busto LaGo (2000), parágrafo II.2.B, p. 2

${ }^{60}$ LACRUZ (1954). 
que niega de lo uno, dice de lo otro") y, tercero, que al establecer el art. 537 que las continuas y aparentes se pueden adquirir a través de una prescripción de veinte años (sin distinguir entre diez para presentes y veinte para ausentes), lo que hizo el Código fue establecer en realidad una excepción al art. 1959, de modo que la prescripción extraordinaria de las citadas servidumbres sería de veinte años en vez de treinta años. De esta manera, las servidumbres discontinuas e inaparentes, en cuanto a la prescripción adquisitiva, siguen rigiéndose por la ordinaria ${ }^{61}$.

La confusión y error patente de las disposiciones decimonónicas; la búsqueda de subterfugios para escabullir a la equívoca prohibición; y el esfuerzo interpretativo de la doctrina destinado al menos a lograr la adquisición mediante prescripción ordinaria de las servidumbres discontinuas, llevó a los códigos civiles de segunda generación o más, a no insistir en el error, eliminando derechamente el requisito de la continuidad para la usucapión (así como para la destinación del padre de familia).

De esta manera, el Código Civil italiano de 1942, coherente con las críticas a la solución francesa y su reproducción en el Código de $1865^{62}$, eliminó la distinción entre servidumbres continuas y discontinuas y desterró a la continuidad como requisito de la usucapión (así como para la destinación del padre de familia) por equívoco e improcedente ${ }^{63}$ a través del art. $1061^{64}$. Quedaron así excluidas de la adquisición por prescripción adquisitiva sólo las servidumbres no aparentes.

${ }^{61}$ LaCRuZ (1954), p. 569; Martínez (1965), pp. 182-183; LaCruz y Luna (2004), No 3, 2, p. 118 y ss.; Busto Lago (2000), parágrafos II.2.C., p. 4 y ss.; Rebolledo (2013), tomo I, pp. 235 a 239.

En México, a pesar de existir texto expreso siguiendo al español, la doctrina tampoco se conforma. Así, De la Mata y Garzón (2014), p. 382, hacen caso omiso a la letra de la ley, concluyendo que no existe ninguna razón para la exclusión, pues la usucapión se encuentra basada en la posesión, y es esta la que debe ser continua.

${ }^{62}$ Expresamente se reconoce que se recogieron las críticas al código derogado, repudiándose el antiguo requisito de la continuidad, BIONDI (2002), p. 602.

${ }^{63}$ En su "Relazione", el ministro de justicia GRANDi (1942), vol. III, No 504 y 506, p. 105, explicó las razones de la eliminación de la distinción: "la exclusión de la usucapibilidad de las servidumbres discontinuas fue justificada por los compiladores del código de 1865 con la consideración que la posesión de tales servidumbres es de entenderse incierta, equívoca y precaria, pudiendo los actos a través de los cuales se ejerce interpretarse como actos de mera tolerancia. Es obvio sin embargo que, cuando se exija la apariencia como condición para la usucapibilidad, el animus utendi iure servitutis no podría explicitarse en forma más tangible: la existencia de obras visibles y permanentes destinadas al ejercicio de la servidumbre vuelven a todos manifiesto el proceso adquisitivo. El requisito de la apariencia es por sí solo idóneo para eliminar el peligro que las servidumbres se establezcan clandestinamente".

${ }^{64}$ Art. 1061. "Servitù non apparenti. Le servitù non apparenti non possono acquistarsi per usucapione o per destinazione del padre di famiglia. Non apparenti sono le servitù quando non si hanno opere visibili e permanenti destinate al loro esercizio". 
Aunque con antelación, pero por influencia de la misma doctrina italiana anterior al nuevo Código Civil, Portugal modificó en 1930 su Código en la materia ${ }^{65}$, eliminando la "continuidad" como requisito de la usucapión (arts. 2272 y 2274 reformados), no obstante mantener la distinción entre servidumbres continuas y discontinuas (ya que el art. 2270 no fue modificado). El nuevo Código Civil de 1966 simplemente eliminó la discutida clasificación, reproduciendo con cambios menores lo ya reformado en los arts. 1547 y $1548^{66}$, también limitando la adquisición por prescripción sólo a las servidumbres aparentes.

Los nuevos códigos civiles que han tenido a la vista el Código italiano, han replicado su solución a la confusión decimonónica. Es el caso, por ejemplo, de los códigos civiles venezolano (arts. 72067), boliviano (arts. 279 , en relación con el art. $277^{68}$ ) peruano (art. 1040) ${ }^{69}$ y brasilero (art. 1379 , en relación con el arts. $1213^{70}$ ).

Por su parte, el Código Civil argentino de 2014 eliminó la distinción entre servidumbres continuas y discontinuas, así como la clasificación entre aparentes y no aparentes. La única división admitida es entre positivas y negativas (art. 2164). Las primeras, se ejercen por actos posesorios (art. 1891), como impresión de signos materiales y, en general, a través del apoderamiento por cualquier modo que se obtenga (art. 1928). La 234 prescripción adquisitiva requiere de posesión o de actos posesorios. Dado que respecto de las servidumbres positivas estos son posibles, procede

${ }^{65} \mathrm{DL} \mathrm{N}^{\circ} 19.126$ de fecha 16 de diciembre de 1930.

${ }^{66}$ Art. 1547. "1. As servidões prediais podem ser constituídas por contrato, testamento, usucapião ou destinação do pai de familia”. Art. 1548. "1. As servidões não aparentes não podem ser constituídas por usucapião".

${ }^{67}$ Art. 720. "Las servidumbres se establecen por título o, por prescripción o por destinación del padre de familia.

La posesión útil para la prescripción en las servidumbres continuas aparentes y discontinuas aparentes, se contará desde el día en que el dueño del predio dominante haya comenzado a ejercerlas sobre el predio sirviente. Respecto a las servidumbres continuas no aparentes y discontinuas no aparentes, la posesión útil para la prescripción se contará desde el día en que el propietario del predio dominante manifieste por escrito al propietario del predio sirviente su pretensión sobre ellas”. El artículo fue modificado el año 1942, siguiendo al Código Civil italiano, introduciendo la expresión 'discontinuas'.

${ }^{68}$ Art. 279. "Las servidumbres aparentes se adquieren por usucapión en las condiciones establecidas para la propiedad de los bienes inmuebles".

${ }^{69}$ Art. 1040. "Servidumbres aparentes. Sólo las servidumbres aparentes pueden adquirirse por prescripción, mediante la posesión continua durante cinco años con justo título y buena fe o durante diez años sin estos requisitos".

${ }^{70}$ Art. 1.379. "O exercício incontestado e contínuo de uma servidão aparente, por dez anos, nos termos do art. 1.242, autoriza o interessado a registrá-la em seu nome no Registro de Imóveis, valendo-lhe como título a sentença que julgar consumado a usucapião. Parágrafo único. Se o possuidor não tiver título, o prazo da usucapião será de vinte anos”. 
su adquisición por este medio, con título o sin título (arts. 1897 y 1898), excluyendo solo a las negativas ${ }^{71}$. Esta última exclusión resulta entendible, por su falta de publicidad.

En España, el éxito del esfuerzo interpretativo de la doctrina en el ámbito jurisprudencial ha sido escaso ${ }^{72}$, manteniéndose los tribunales superiores apegados a la equívoca interpretación original. En cambio, se han logrado avances importantes a través de las leyes civiles forales, pues buena parte de estas ya han eliminado la exigencia de la continuidad (v.gr., los arts. 568 y 569 del $C C$ de Aragón $^{73}$; la ley 397 del Fuero Nuevo de Navarra ${ }^{74}$; el art. 88.1 de la Ley de Derecho Civil de Galicia ${ }^{75}$ y el art. 128 de la ley del Derecho Civil Foral del País Vasco ${ }^{76}$ ).

${ }^{71}$ Lorenzeti (2015), $\mathrm{N}^{\mathrm{o}}$ IX, p. 59; Culaciati (2015), $\mathrm{N}^{\mathrm{o}}$ v, p. 269.

${ }^{72}$ Sentencia de la STSJ de Navarra de 20 de septiembre de 1991 aplicó interpretación del consentimiento tácito de Ángel Luis Rebolledo. Citado por CerdeIrA (2000), p. 29, n. 58.

${ }^{73}$ Estas disposiciones distinguen solo entre servidumbres no aparentes y aparentes para regular la usucapión, admitiendo la adquisición por este modo de las discontinuas, criterio que no tiene ninguna importancia. Se rechaza, en cambio, la adquisición de servidumbres negativas y las de vista y luces por prescripción adquisitiva. Es más, en la exposición de motivos del $C C$ de Aragón expresa: "el sistema no se corresponde con el del Código civil ni con las consecuencias que en él tienen las clasificaciones de servidumbres positivas o negativas, continuas o discontinuas, aparentes o no aparentes. La regulación aragonesa estribaba en esta última distinción (aparentes y no aparentes), como explicaba la Exposición de Motivos de la Compilación de 1967, aunque la extraordinaria concisión de las normas compiladas ocasionaba que se aplicaran indebidamente normas del Código civil que responden a criterios muy distintos, con las consecuencias de la diversidad de opiniones doctrinales y la consiguiente inseguridad jurídica y el aumento de la litigiosidad".

La regulación aragonesa tiene por fundamento precisamente en cuanto al fondo, la circunstancia que posesión continua y ejercicio continuo son dos conceptos diferentes, requiriendo la usucapión de la primera como requisito, siendo indiferente la segunda; históricamente, porque el Derecho aragonés no exigía la continuidad; y modernamente, porque legislaciones como la italiana de 1942 ya habían desechado la continuidad. ARGUDO (2013), tomo II, p. 883.

${ }^{74}$ Consagra esta disposición la usucapibilidad de toda clase de servidumbres y la adquisición de las aparentes discontinuas. La compilación del Derecho Civil foral de Navarra fue aprobada por ley 1/1973, de 1 de marzo (corr. err., 1974).

${ }^{75}$ Ley 2/2006, de 14 de junio, Comunidad Autónoma de Galicia. Esta ley no distingue entre servidumbres continuas y discontinuas, estableciendo como regla general la adquisición de aquellas de paso por su posesión pública, pacífica e ininterrumpida durante el plazo de veinte años, contados desde el momento en que empieza a ejercitarse. Afirma Busto (2013), tomo II, pp. 429-430 que el aspecto más destacado del artículo y que lo justifica y constituye la prístina razón de ser de la regulación de la servidumbres de paso por el legislador gallego, es constituido por el hecho de que se posibilite la adquisición por usucapión extraordinaria -sin buena fe ni justo título- de las servidumbres de paso, porque este modo de adquirir presenta una radical diferencia respecto del régimen del Código Civil.

${ }^{76}$ Aprobado por ley 3/1992, de 1 de julio. La exposición de motivos de esta ley expresamente señala que en razón de "que conforme al Código Civil las servidumbres 
Finalmente en Francia, no han habido hasta la fecha cambios en el ámbitolegislativo. Sin embargo, existe la conciencia histórica del error en que incurrió el Code al confundir la continuidad de la causa del gravamen con la continuidad de la posesión. De hecho, hemos visto la multiplicidad de subterfugios que se han creado para evadir la limitación, así como la interpretación avanzada por importantes autores para dar solución al problema, admitiendo, al menos, la adquisición por prescripción ordinaria de las servidumbres discontinuas. Por todo ello, parece que poca es la vida que le quedan a los actuales textos de los arts. 688, 690 y 691.

En efecto, en el proyecto de reforma al Código Civil francés en materia de bienes de la Asociación Henri Capitant, simplemente se acaba con la distinción entre servidumbres continuas y discontinuas, admitiéndose la adquisición por prescripción sobre la base de la posesión del derecho ${ }^{77}$. La explicación del grupo de trabajo a estos cambios fue, primero, lo difícil que resulta la aplicación de dichas categorías; en segundo lugar, se reconoce que estas son inapropiadas para la adquisición por usucapión y, en tercer lugar, porque siendo la evidencia y la manifestación concreta de una servidumbre y su ejercicio los elementos necesarios para la adquisición, tales categorías resultan superfluas, siendo suficiente que la servidumbre se manifieste a través de obras exteriores o por una actividad humana $236 \quad$ aparente y periódica ${ }^{78}$.

\section{ADMISIÓN DE LA PRESCRIPCIÓN ADQUISITIVA DE laS DENOMinadas “SERVidumbres discontinuas” en Chile}

\section{Reconocimiento de la doctrina nacional de los equívocos fundamentos de la inadmisibilidad de la adquisición de las servidumbres discontinuas por prescripción adquisitiva}

Como se vió en el acápite I, el Código Civil chileno se limitó en los arts. 822,881 y 882 a reproducir en lo sustancial la recepción francesa de la confusión entre servidumbre continua y posesión continua, así como sus disposiciones transaccionales del Derecho Consuetudinario. Igualmente, se han seguido y reproducido en nuestro país los argumentos que funda-

de paso son imprescriptibles (art. 539), ha permitido plantear numerosos litigios en los que se deniega la servidumbre sobre derechos de paso de uso muy antiguo. El artículo 128 de esta ley recoge de nuevo la adquisición por prescripción".

${ }^{77}$ Art. 615. "Les servitudes qui se manifestent par des ouvrages extérieurs ou par une activité humaine apparente et renouvelée peuvent s'acquérir par la possession dans les conditions des articles 549 et 554". PÉrinet-MARQuet (2009), p. 136.

${ }^{78}$ Bergel (2009), pp. 91-92. 
mentarían la exclusión de las servidumbres discontinuas de la prescripción adquisitiva.

Pero la dependencia francesa de nuestro Derecho en la materia, también ha permitido que la mayoría de los autores nacionales tengan conciencia de la confusión y la reconozcan, así como, particularmente, que respecto de una servidumbre que el art. 822 califica de discontinua, puede tener lugar una "posesión continua"79.

$\mathrm{Al}$ respecto Luis Claro Solar, frente a la clasificación de continuas y discontinuas, afirmaba que "la continuidad de la servidumbre no puede confundirse con la continuidad de la posesión", por cuanto la "posesión es continua cuando el poseedor hace los actos de goce que la naturaleza de la cosa permite" ${ }^{80}$. Y luego, comentando el art. 882 decía: "la disposición puede ser rigurosa con respecto a servidumbres discontinuas aparentes, ejercidas con frecuencia durante una larga posesión”, ya que

"una servidumbre de tránsito ejercida por un camino especialmente destinado a ella, puede haber sido usada diariamente para las necesidades de un predio; y sin embargo no sería admisible la prescripción para adquirirla, a pesar de que la frecuente repetición del tránsito por el camino no pueda estimarse como simple tolerancia de algo que no imponga gravamen, cuando ha venido repitiéndose muchos años y con diferentes propietarios del predio sirviente o de ambos predios" $"$.

Por ello Eduardo Varas derechamente, luego de reproducir y concordar con el pensamiento de Marcel Planiol, expresaba que "estas críticas nos hace considerar preferible dejar la prescripción de las servidumbres entregada a los principios generales" ${ }^{2}$.

Así, las críticas a la mera tolerancia como clásico fundamento para desechar la posibilidad de una posesión de servidumbres discontinuas, en concordancia con la doctrina extranjera, han estado también presente

${ }^{79}$ Se suman a los autores que luego se citan en el cuerpo del artículo, ArELLANo (1949), No 54, p. 75; PeÑallillo (2016), No 203, pp. 408-409.

${ }^{80}$ Claro Solar (2015), tomo iv, vol. $9^{\circ}$, No 1350, p. 60; Claro Solar (1904), p. 192 y Claro Solar (2010), p. 735. En idéntico sentido, Vodanovic (2016), tomo II, N $^{\circ}$ 1271 ?, pp. 321-322 quien afirma adicionalmente que "la exigencia de continuidad y de apariencia de la servidumbre no tiene relación alguna con las calidades de continuidad y de publicidad de la posesión".

${ }^{81}$ Claro Solar (2015), tomo iv, vol. $9^{\circ}$, No 1648, p. 322; Claro Solar (1904), p. 188 y Claro Solar (2010), p. 731. El autor cita a François Laurent, concordando entonces con la crítica francesa a las reglas consagradas en el Code.

${ }^{82}$ VARAS (1925), pp. 405-406. 
entre nuestros doctrinarios. Claro, porque en el art. 2499 la mera tolerancia es, en realidad, un requisito para la aplicación de la disposición y no, en cambio, como se ha pretendido, una consecuencia de la naturaleza de la supuesta servidumbre ejercida. En efecto, si concurre y se prueba que hay mera tolerancia, los actos que se ejecuten en virtud de ella no confieren posesión, ni dan fundamento a prescripción alguna. Por el contrario, si la mera tolerancia no concurre y así se prueba, los actos sí pueden ser constitutivos de posesión y sí pueden dar fundamento a la prescripción, resultando la norma inaplicable.

Se recuerda sobre el particular que la mera tolerancia (como la posesión) es una cuestión de hecho, y como tal se encuentra sujeta a prueba. Cuestión distinta es a quien corresponde el onus probandi. En este sentido, lo que el art. 2499 a lo más consagró fue una presunción simplemente legal en favor de los propietarios que admite prueba en contrario. Pero esta es solo la regla clásica probatoria que hemos heredado, pudiendo perfectamente haber sido la contraria o, bien, modificarse en el futuro. De hecho, modernamente algunas legislaciones invierten la carga de la prueba $^{83}$.

De manera que, según la regla vigente, se presume, por ejemplo, que los actos que forman parte del contenido de una servidumbre discontinua 238 ejecutados sobre un predio ajeno, son actos de mera tolerancia y no hacen nacer gravamen alguno sobre este último, salvo que el interesado pruebe que en verdad eran actos posesorios. Y desde luego, cada vez que el ejecutante de dichos actos esté en condiciones de exhibir un título, nulo o a non domino (como en el segundo caso de la situación de nulidad y tercera situación vistas en el acápite II), la mera tolerancia desaparece.

Por ello los autores nacionales reconocen entonces que, cumpliéndose ciertas circunstancias, se está en presencia de actos posesorios y no de mera tolerancia. Al respecto Antonio Vodanovic es claro en señalar:

"el uso público, excluyente y continuo de una cosa, sin oposición de su dueño, hace presumir que éste presta su aquiescencia y constituye un acto de posesión apto para usucapir, o sea, para adquirirlo por prescripción adquisitiva. Con mayor razón merecerá este calificativo la construcción de una obra sólida y estable en el terreno vecino" ${ }^{4}$.

${ }^{83}$ El art. 82 de la ley N²/2006 sobre Derecho Civil de Galicia dispone: "corresponde al dueño del predio presuntamente sirviente acreditar que el paso se ejercitó por mera tolerancia".

${ }^{84}$ Vodanovic (2016), tomo II, No 788, p. 25. Igualmente, PeÑallillo (2016), No 205, p. 411; Arellano (1949), No 67, p. 86. 
Lo expresado se traduce en que el inc. $3^{\circ}$ del art. 2499 no dice que todo ejercicio de hecho de una servidumbre discontinua (de tránsito o pasto) importe siempre actos de mera tolerancia y nunca de posesión. Ello a lo más es una presunción de la ley. Porque la disposición claramente dice "el que tolera", cuestión sólo de hecho, que admite que se pruebe en contrario que no ha existido tolerancia en el tránsito o pasto, sino posesión de la servidumbre respectiva.

Nótese al respecto que el art. 802 impone responsabilidad al usufructuario por las servidumbres que sobre el predio haya dejado adquirir por su tolerancia, lo que solo sería posible si los actos, inicialmente de mera tolerancia, con la regularidad adquirieron el carácter de posesorios. De lo contrario, a la luz del art. 2499, la disposición sería inaplicable, puesto que nunca por mera tolerancia un tercero podría haber adquirido un de recho.

A mayor abundamiento, han sido los mismos autores patrios quienes les han informado al medio nacional que los tribunales franceses han debido recurrir a subterfugios para orientar sus decisiones en el sentido de admitir la prescripción de servidumbres discontinuas ${ }^{85}$. Es decir, han puesto a disposición de nuestros juristas y jueces las vías a través de las cuales superar las dificultades creadas por los textos del Código Civil.

Luego, aceptada la confusión y el error regulatorio al cual ha llevado, tanto por la doctrina comparada como chilena, y la orientación de la legislación civil extranjera posdecimonónica, lo razonable es su corrección y no persistir en la confusión y en el error. La regla de la imprescriptibilidad de las servidumbres discontinuas científicamente está muerta; en un buen número de legislaciones ya se le otorgó el certificado de defunción como hemos visto; y en el resto no puede sino reconocerse su estado agónico.

Desde esta perspectiva, sería óptimo una reforma de las actuales disposiciones del Código de Andrés Bello. Pero mientras ello no ocurra, la doctrina debe avanzar en la revisión de la interpretación hasta ahora efectuada de los artículos pertinentes, a fin de alcanzar conclusiones que superen la reconocida confusión y el error. Ello permitiría a los tribunales contar con nuevas lecturas que les entreguen fundamentos adecuados y ajustados al texto del Código Civilpara declarar la prescripción adquisitiva de las servidumbres discontinuas. En los números siguientes, se exponen dos posibles caminos que podrían seguirse, y un tercero que constituye nuestra propuesta y la vía que entendemos más ajustada al tenor de los artículos involucrados y las circunstancias actuales.

${ }^{85}$ VARAS (1925), pp. 406-407; VodANOVIC (2016), tomo II, No 1162, p. 232. 


\section{2. "Elusión" de la discontinuidad a través de subterfugios}

En Chile no han faltado quienes derechamente soliciten a los tribunales la utilización de subterfugios para dar solución a las tres situaciones problemáticas planteadas en el acápite II, tal como ha ocurrido en la doctrina y jurisprudencia extranjera ${ }^{86}$. En lo fundamental, esta alternativa consiste en dar a los hechos y actos ejecutados por el agente sobre un predio ajeno una interpretación que entregue como resultado la configuración de un derecho con contenido y objeto diferente al de una servidumbre discontinua.

Desde luego, entre las posibilidades se encuentra concluir que lo adquirido por el poseedor fue el dominio o la copropiedad del terreno en que se ejecutaron los actos. También que lo poseído fue un derecho real distinto al dominio, pero diferente a una servidumbre. Mas, estas vías seguidas fundamentalmente en Francia, resultan complejas en Chile en razón de la imposibilidad de poseer contra título inscrito para el primer caso o, bien, por la imposibilidad de crear nuevos derechos reales, dado el numerus clausus que rige en nuestro país, para el segundo caso.

Dado que las servidumbres sí son reconocidas como derecho real por la ley, pero no existe limitación para la creación de ellas, pareciera más factible sostener la posesión y adquisición de servidumbres continuas. Así, podría afirmarse que el gravamen que impone una de tránsito no tiene por objetivo el paso, sino soportar permanentemente la obra hecha para pasar ${ }^{87}$. También podría entenderse que si para la obtención de un servicio en el predio sirviente se ha recurrido a la realización de obras (por ejemplo, la apertura de un camino entre cerros y bosques con maquinaria pesada), estas por sí mismas darían cuenta de una ejecución "continuada" del servicio, sin necesidad de un hecho actual del hombre. En ambos casos podría hablarse de una especie de "servidumbre de obra".

En tal contexto, bastante interesante resulta la distinción que se ha logrado hacer entre servidumbre de "tránsito" y de "viaducto" (o con el nombre que resulte preferible). La de "tránsito", tiene simplemente por objetivo el paso, correspondiendo a la servidumbre que el Código Civil considera "discontinua" (arts. 822 y 824). La de "viaducto", tiene por

${ }^{86}$ VARAS (1925), p. 407, luego de reproducir las críticas de la doctrina francesa, afirma: "únicamente en virtud de subterfugios semejantes a los inventados por la jurisprudencia francesa pueden nuestros tribunales considerarla adquirida por prescripción”.

${ }^{87}$ Rebolledo (2013), tomo I, p. 94, citando a González-Alegre y a Manresa. El mismo autor sintetiza la crítica, fundada en que la utilidad solo tendría lugar cuando el hombre actúa, de manera que el gravamen correlativo se produce cuando se transita y no por el soporte de la vía (véanse autores citados con esta postura en n. 18 de la obra). 
objetivo las obras a través de las cuales tiene lugar un tránsito o paso, debiendo ser calificada de "continua", pues sería análoga a la servidumbre de acueducto (o de oleoducto, o gaseoducto, o electroducto, etc.). Esta analogía tiene especialmente en cuenta la circunstancia de que la continuidad o discontinuidad no depende del mayor o menor intervalo entre el paso del respectivo contenido: que el agua deje de escurrir en algunos momentos del día, año o mes, no modifica la naturaleza de continua de la servidumbre de acueducto. Pues bien, el mismo criterio debiera aplicarse a la de viaducto (el paso de hombres o vehículos, más o menos interrumpido, no le quita el carácter de continua).

Si bien esta vía interpretativa a través de subterfugios permite superar la confusión histórica así como resolver las situaciones tratadas en el acápite II, presenta al menos tres defectos:

- El primero, la alteración conceptual de los derechos en la práctica ejercidos, a fin de evitar la subsunción del caso en el concepto de discontinuidad del art. 822.

- El segundo, provoca una dispersión de la solución, ya que en definitiva para cada caso, el derecho o la servidumbre continua reconocida puede ser muy distinta, según los hechos del caso particular y el criterio aplicado a él por el tribunal. Ello conlleva, desde luego, inseguridad jurídica, salvo que se produzca una uniformidad jurisprudencial y doctrinal, lo que, además, de ser muy difícil, exige un largo transcurso de tiempo.

- Y el tercero, que no profundiza el verdadero sentido y alcance de las disposiciones del Código Civil vigentes, sino, simplemente, constituye una forma de eludir "la" interpretación tradicional, en particular de la "discontinuidad".

\section{Las servidumbres discontinuas y las inaparentes} pueden adquirirse por prescripción adquisitiva concurriendo un título

No se ha estudiado en Chile la posibilidad de aplicar las interpretaciones de los artículos correspondientes del Código Civildesarrolladas en Francia, Italia y España (referidas en el precedente acápite), y que permiten a los poseedores regulares de servidumbres con título (en especial a non domino), adquirir el derecho mediante prescripción adquisitiva. Ciertamente los textos nacionales presentan algunas diferencias relevantes con el Código francés, español e italiano de $1865^{88}$. No obstante, creemos que entregan

${ }^{88}$ Efectivamente, en el art. 2508 Andrés Bello estableció como prescripción ordinaria los tres años justinianeos para la adquisición del dominio de los bienes muebles (hoy dos), y diez años (hoy cinco años) para la adquisición del dominio de bienes raíces, pero 
suficiente margen como para utilizar el mismo método y fundamentos, permitiendo llegar a conclusiones similares o, incluso, mejores que en los citados países. A continuación desarrollaremos esta posible reinterpretación.

El art. 2498 dispone claramente que se ganan por prescripción de la misma manera que el dominio "los otros derechos reales que no están especialmente exceptuados". El art. 2512 no hace más que ratificar esta disposición, al señalar en su inc. $1^{\circ}$ que "los derechos reales se adquieren por la prescripción de la misma manera que el dominio, y están sujetos a las mismas reglas".

De esta forma, dado que las servidumbres activas son un derecho real (art. 577), no cabe sino concluir que en principio, cualquiera sea su clase, les son aplicables las mismas reglas en materia de prescripción adquisitiva que al dominio. Ello implica que quedan sujetas tanto a las reglas de la prescripción ordinaria como a las reglas de la prescripción extraordinaria.

Empero, también el art. 2498 deja en claro que todo el régimen de la prescripción adquisitiva funciona en relación con los derechos reales de servidumbre, salvo respecto de aquellos "que [...] están especialmente

agregando que cada dos días se cuentan entre ausentes por uno solo para el cómputo de los años (así llegaba a los veinte justinianeos entre ausentes). Luego, en el art. 2511 reguló el tiempo de la prescripción extraordinaria, indicando obviamente como plazo treinta años (hoy diez años). A continuación, en materia de servidumbres, en el art. 882 recogió y fusionó los arts. 690 y 691 del $C C$ francés, pero, a diferencia de los arts. 690 francés y 629 italiano (de 1865), en vez de indicar como plazo treinta años, señaló diez años. Así, el argumento de la doctrina francesa e italiana en orden a que lo excluido es solamente la prescripción extraordinaria para las servidumbres discontinuas por posesión irregular y no la prescripción ordinaria por posesión regular, resultaría imposible de ser acogido en Chile.

Por otra parte, a diferencia del Code, y coincidiendo con los códigos italiano de 1865 y español, en el art. 2512 regla $2^{\text {a }}$ dispuso que los derechos reales se adquieren de la misma manera que el dominio, pero "salvo" el derecho de servidumbre, el cual se adquiriría según el art. 882. Esta redacción presenta una relevante diferencia con el Código italiano derogado, que no consideraba la excepción; y, respecto al Código español, que sí la menciona, significa también una diferencia importante, en cuanto este último la incorporó solo en el artículo sobre prescripción extraordinaria (art. 1959), mientras que el chileno en una norma general (art. 2512).

Por último, el Código español estableció en el art. 537 un plazo de veinte años, que no coincide con los treinta de la prescripción extraordinaria, pero tampoco coincide exactamente con la prescripción ordinaria, dividida en los plazos de diez años para los presentes y veinte años para los ausentes. Ello permite a los autores hispanos interpretar (en relación con los arts. 1957 y 1959), que el plazo de veinte años del art. 537 es un plazo especial de prescripción extraordinaria, admitiendo, entonces, que sí es posible la prescripción ordinaria de diez años. En Chile en cambio, la excepción a la regla general sobre la prescripción de los demás derechos reales del art. 2512 y el plazo de diez años (hoy cinco años) del art. 882 inc. $2^{\circ}$, coinciden con la prescripción ordinaria, lo que dificulta una interpretación de las disposiciones idéntica "a la española". 
exceptuados". La norma, junto con admitir que pueden haber excepciones, dispone que ellas deben estar establecidas en la ley.

Efectivamente, el art. 2512 establece como segunda excepción que "el derecho de servidumbre se adquiere según el art. 882”. Ya se recordó en el acápite I que la doctrina tradicional ha entendido que ello implicaría que las servidumbres continuas y las aparentes son excluidas del régimen general de prescripción y, por tanto, de la distinción entre prescripción ordinaria y extraordinaria, según lo dispuesto en el inc. $2^{\circ}$ del art. 882. Y que por el contrario, las discontinuas e inaparentes serían excluidas de toda prescripción, conforme el tenor del inc. $1^{\circ}$ del mismo artículo. Sin embargo, estas conclusiones no parecen conformarse con el real tenor de las normas positivas involucradas.

En primer lugar, art. 2512 en su excepción segunda no dice que respecto de las servidumbres se excluye o no una determinada clase de prescripción (ordinaria o extraordinaria). Solo se remite al art. 882. Ello es muy distinto de los que ocurre con la excepción primera del art. 2512, referida al derecho de herencia y el censo, que expresamente aplica la prescripción extraordinaria, desechando la ordinaria. Incluso más, el proyecto de 1847 en su art. 716 inc. $3^{\circ}$ disponía que "[los] derechos de censo i de servidumbre se adquieren en jeneral por la prescripción ordinaria". Sin embargo, esta limitación en la aplicación de la usucapión desapareció en el proyecto de 1853.

En segundo lugar, y a pesar de lo que ha dicho la doctrina y la jurisprudencia dominante, en parte alguna el inc. $1^{\circ}$ del art. 882 dice que las servidumbres discontinuas y las inaparentes no pueden adquirirse por prescripción, sea ordinaria o extraordinaria. El punto es muy relevante, pues el art. 2498 exige, para que un derecho real no pueda adquirirse por prescripción adquisitiva, que exista una norma legal que explícitamente diga lo contrario ("especialmente exceptuados").

En tercer lugar, el inc. $1^{\circ}$ del art. 882 introdujo una regla muy distinta: las servidumbres discontinuas y las inaparentes "sólo pueden adquirirse por medio de un título". Sobre el sentido y alcance de "título" en la disposición, nos parece que la doctrina tradicional es correcta en su interpretación, en orden a entender que se refiere a actos jurídicos como causa o antecedente jurídico de la adquisición. Sin embargo, a través de dicho acto, nada se adquiere, como hemos recordado en el acápite I, porque falta un modo.

En cuarto lugar, el inc. $1^{\circ}$ del art. 882 no desecha expresamente ningún modo de adquirir, lo que desde luego incluye a la prescripción adquisitiva. Cuestión distinta es que, cualquiera sea el modo que opere, para que produzca el efecto adquisitivo esperado, necesariamente debe cumplirse con un requisito concreto: que cocurra con título. La norma en 
este punto es clara, aunque errónea en su redacción. Como dice Alejandro Guzmán en relación con las servidumbres discontinuas y a las inaparentes, "sólo pueden adquirirse en virtud de un título" ${ }^{89}$, lo que es distinto a decir "sólo pueden adquirirse por medio de un título", dado que este no puede producir ningún efecto adquisitivo.

De tal manera que el art. 882 inc. $1^{\circ}$ modifica las reglas generales sobre prescripción adquisitiva del Código Civil, pero en cuanto introduce un requisito obligatorio en materia de prescripción de servidumbres que aquellas no imponen (siempre debe concurrir un título). Sin embargo, la alternación no sería más que la recepción y ratificación de la regla general que históricamente ha regido a las discontinuas y a las inaparentes, a la cual nuestro Código se conformó ${ }^{90}$.

En quinto lugar, ratifica lo anterior la parte final del inc. $1^{\circ}$ del art. 882: "ni aún el goce inmemorial bastará para constituirlas". O sea, si no concurre un título, aunque se ejerza de facto el derecho de servidumbre discontinua o inaparente, y sin importar el tiempo por el cual se prolongue ese ejercicio, la ley impide sencillamente la adquisición del derecho.

Es en este sentido que resultaría concordante el art. 882 inc. $1^{\circ}$ con el art. 2499 inc. $3^{\circ}$ (y, por tanto, con la doctrina tradicional), en cuanto el ejercicio de hecho de una servidumbre discontinua o inaparente sería un 244 acto de mera tolerancia que no confiere posesión ni permite su adquisición por medio de usucapión, toda vez que falta el requisito esencial del título.

En sexto lugar, el inc. $1^{\circ}$ del art. 882 solo exige un título. No señala si debe ser justo, injusto, otorgado por el propietario o a non domino. La disposición no reglamenta este detalle, dejando entregada la exigencia del tipo de título al modo de adquirir que llegue a operar en la práctica conforme a las reglas generales. Y donde la ley no distingue, no le está permitido al intérprete distinguir.

En séptimo lugar, de acuerdo con lo expresado en precedencia, las servidumbres discontinuas y las inaparentes pueden adquirirse a través de prescripción adquisitiva, conforme a las reglas generales del Código Civil. Desde luego, siempre que concurra un título. Si este es acompañado de los demás requisitos legales y configuran una posesión regular, a través de la prescripción ordinaria de cinco años; si por el contrario se cumplen los demás requisitos legales, pero la posesión es irregular, mediante la prescripción extraordinaria de diez años. Luego, respecto de esta última, la exigencia de que siempre el poseedor pueda acreditar que tiene un

${ }^{89}$ GuZMÁn (2006), p. 204.

${ }^{90}$ Op. cit., p. 208 señala expresamente que a falta de tradición (escritura pública), "recobra su vigencia el principio natural de que el ejercicio de hecho de un derecho real, provisto de un título, es verdadera cuasiposesión". 
título impuesto por el art. 882 inc. $1^{\circ}$, significa una excepción a la regla general de la prescripción adquisitiva extraordinaria, en cuanto deja sin aplicación el art. 2510 regla $1^{\mathrm{a}}$ ("no es necesario título alguno").

En octavo lugar, el art. 882 inc. $2^{\circ}$ establece una alternativa para la adquisición de las servidumbres continuas y aparentes, negada a las discontinuas y a las inaparentes en el inciso primero, y expresada en términos simétricos al inciso primero. Desde luego, pueden las continuas y aparentes adquirirse por un modo en que concurra un título, como es permitido para las discontinuas y las inaparentes. Pero además, pueden adquirirse por prescripción, eximiendo a esta adquisición de la concurrencia de un título y además estableciendo que bastará el transcurso de un quinquenio.

De esta manera, y en lo que tiene razón la doctrina tradicional, el art. 882 en su inc. $2^{\circ}$ contiene una excepción a los arts. 2506, 2510 regla $1^{\mathrm{a}}$ y 2511 en favor de las servidumbres continuas y aparentes en virtud de las particulares características que presentan. Y así, a diferencia de las discontinuas y las inaparentes, admite respecto de las continuas y aparentes su adquisición mediante una prescripción adquisitiva única de cinco años sin título. Las discontinuas y las inaparentes en cambio siempre requieren de título, y si este es justo podrán optar a la prescripción ordinaria de cinco años. Si en cambio es injusto, solo podrán optar a la prescripción extraordinaria de diez años ${ }^{91}$.

Por tanto, el art. 882 inc. $2^{\circ}$ introdujo una excepción a las reglas generales de la prescripción adquisitiva extraordinaria (específicamente al art. 2511), en cuanto solo admite para las servidumbres continuas y las aparentes una posesión irregular de cinco años (incluso sin título).

Si bien la reinterpretación precedente nos parece bastante consistente, presenta dos defectos importantes. El primero, ella solo resultaría aplicable a la segunda y tercera situación tratadas en el acápite II, excluyendo entonces a la situación problemática que más regularmente tienen lugar en Chile, como es el ejercicio de hecho (sin título) de servidumbres de tránsito. Desde esta perspectiva, el esfuerzo interpretativo para superar la confusión histórica perdería buena parte de su valor. En segundo lugar, se ajusta técnicamente al método seguido en Francia, Italia y España, y a casi todos los elementos que presentan los textos del Código Civil, salvo a uno muy relevante que queda inconsiderado: el art. 882 inc. $1^{\circ}$, a diferencia de lo códigos citados, alude a "las servidumbres discontinuas $d e$

${ }^{91}$ Esta lectura nos parece que es respaldada por GuZMÁn (2006), p. 208 (en relación con lo expresado en p. 204) quien, junto con reconocer que el art. 882 inc. $2^{\circ}$ permite una cuasiposesión de las servidumbres continuas y de las aparentes por acto unilateral, asevera que la disposición "se trata más bien de una norma excepcional” frente al principio natural de que es necesario estar provisto de un título para entrar en la posesión de servidumbres. 
todas clases". En razón de estos defectos, la interpretación antes expuesta debe someterse a una ulterior corrección.

\section{Relectura del artí. 882 del Código Civil. Prescripción adquisitiva de las servidumbres continuas de alguna clase}

Según reza el art. 882 inc. $1^{\circ}$, solo pueden adquirirse en virtud de un título "las servidumbres discontinuas de todas clases y las servidumbres continuas inaparentes". Pues bien, la expresión "de todas clases" no se encuentra en el Código Civil francés, ni tampoco en otros que le siguieron y que pudieron ser fuente del Código chileno ${ }^{92}$. Su origen es, con bastante probabilidad, atribuible a Claude Delvincourt, cuyo Curso de código de Napoleón constituyó como, es sabido, fuente directa para Andrés Bello en la redacción de varios artículos. Precisamente, a propósito de los modos de establecimiento de las servidumbres, el autor francés afirmaba: "les servitudes discontinues, quelles qu'elles soient [...]"93.

En cuanto al significado dado por Delvincourt a sus palabras, en una de las notas comprendidas en la citada obra, señala que ellas querrían decir "aparentes o no aparentes" ${ }^{4}$. Creemos, sin embargo, que la interpretación de la expresión, por mucho que la haya tomado Bello para la redacción del art. 882 de Delvincourt, no puede quedarse simplemente limitada a los dichos de la nota. Debe considerarse una serie de otros elementos.

En este sentido, no puede pasar desapercibido que el art. 691 inc. $1^{\circ}$ del $C C$ francés, fuente directa junto al art. 690 de nuestro art. 882, dice "les servitudes discontinues, apparentes ou non apparentes". Y probablemente, Delvincourt soloi explicó "quelles qu'elles soint" en sus notas reproduciendo las palabras del Code y, por ende, lo que la doctrina de la época decía. Los autores nacionales, de hecho históricamente, han efectuado la misma operación ${ }^{95}$. Empero, Bello en este punto no copia el tenor de la norma francesa ni tampoco la explicación de Delvincourt en su nota, como otras veces sí lo hizo ${ }^{96}$. O sea, el redactor de nuestro Código Civil tuvo a la vista todas las posibilidades de escribir en el art. 882 "las servidumbres discontinuas aparentes o no aparentes..." y no obstante ello, no lo hizo. Prefirió aquella expresión de su inspirador francés, que tenía la

${ }^{92}$ Se replica, en cambio, en aquellos códigos que siguieron al chileno, v.gr., arts. 939 del $C C$ colombiano; 926 del $C C$ ecuatoriano; 884 del $C C$ salvadoreño; 633 del $C C$ uruguayo.

${ }^{93}$ Delvincourt (1813), tomo I, p. 170.

${ }^{94}$ Op. cit., p. 568, nota 1 (en "Notes et explications, page 170").

${ }^{95}$ Ejemplo de ello es Claro Solar (1904), p. 191 y Claro Solar (2010), p. 734.

${ }^{96}$ Por ejemplo, el art. 830 inc. $2^{\circ}$, respecto del cual hemos destacado que tuvo su fuente en las explicaciones de Claude Delvincourt al art. 701 del $C C$ francés, en Rosso (2014a), p. 339 y ss. 
mayor amplitud potencial. Luego, algo advirtió y algo distinto quiso decir.

No parece, entonces, razonable mantener una lectura restrictiva de la expresión que lleve a igual resultado que el mismo redactor parece que quiso evitar. Por el contrario, lo correcto más bien es indagar si hay un sentido y alcance distinto para la expresión "de todas clases". Sobre todo porque la confusión y el error en que incurrió el legislador francés fueron advertidos por el mismo Delvincourt y, por medio de este, conocidos por Andrés Bello. Es más, hay constancia que hubo en este punto particular influencia del primero en el segundo.

En efecto, las "servidumbres de vista" fueron consideradas por el legislador francés y sus seguidores como servidumbres "continuas", admitiéndose la adquisición a través de prescripción adquisitiva. El problema estriba en que la existencia de una ventana o balcón no parecen generar ningún gravamen a los predios vecinos, a menos que alguien se asome a través de ellos; es decir, la causa del gravamen es un hecho del hombre, igual como ocurre con las servidumbres de tránsito.

Frente a tal dispar criterio utilizado por el Código francés, Delvincourt simplemente admitió:

"confieso que mal sé distinguir en cuanto al fondo una diferencia entre la servidumbre de vista y aquella de paso manifestada con un signo externo, por ejemplo, con una puerta sobre el territorio del vecino" ${ }^{\prime 97}$.

Y Andrés Bello, atento a las explicaciones del jurista galo, y advirtiendo el error, elimina del Código Civil la calificación de continua que figuraba para las servidumbres de vista en el proyecto de $1853^{98}$.

En tal contexto, lo primero que se advierte es que la expresión "de todas clases" figura en el inc. $1^{\circ}$ del art. 882 como un complemento adjetival del adjetivo 'discontinuas' y no del sustantivo 'servidumbres'. De modo que lo que la frase está diciendo en realidad es que las servidumbres que presentan discontinuidad de todas las clases, esto es, de todas las clases posibles de discontinuidad, además de las continuas inaparentes, solo pueden adquirirse en virtud de un título. Por el contrario, si una servidumbre presenta "continuidad" de alguna clase, no queda subsumida en la hipótesis de la disposición y, por ende, no puede exigirse título para que opere el modo respectivo.

${ }^{97}$ Delvincourt (1813), tomo I, p. 568, n. 1 (en "Notes et explications, page 170").

${ }^{98} \mathrm{El}$ art. 971, hoy art. 822, en vez de contener como ejemplo la servidumbre de acueducto, decía "como la que consiste en que una casa tenga un mirador que domine a la casa vecina". 
Sobre el particular, como hemos visto en el acápite III, una servidumbre puede ser calificada de "continua" o "discontinua" a partir de la aplicación de distintos criterios, dando lugar, en consecuencia, a diversas clases o tipos de continuidad o discontinuidad.

Así puede señlarse que, en primer lugar, las servidumbres pueden ser continuas o discontinuas atendiendo al criterio de la posesión. Conforme a este, una servidumbre puede ser "continua" o "discontinua" según si concurre en el caso un ejercicio ininterrumpido del contenido de ellas (cuestión de hecho que tendrá que probarse) o, bien, de forma interrumpida. Al criterio de la posesión continua o discontinua acude el Código Civil en diversas normas (arts. 719 y 2500), aunque la mayoría de las veces bajo la terminología citada de no interrumpida o interrumpida, pues el acento se pone en el tiempo (arts. 918, 2501, 2507, 2510 regla $\left.3^{\circ}\right)$. Si se acredita en la especie una posesión continua, significa que existe al menos una clase de continuidad (continuidad en la posesión) y, por tanto, no estamos en presencia de una servidumbre discontinua de todas clases.

En segundo lugar, una servidumbre puede ser "continua" o "discontinua" atendiendo a su causa, criterio que recoge el art. 822 del Código Civil. Es decir, una servidumbre calificada bajo los términos de este artículo, podrá presentar una continuidad de causa o una discontinuidad de causa. 248 Cuestión distinta es que la determinación de cuándo es continua o cuándo es discontinua según esta disposición, ha sido uno de los problemas más debatidos en doctrina y jurisprudencia. Empero, si un tribunal determina según los antecedentes del caso que es continua porque se ejerce o se puede ejercer continuadamente sin necesidad de un hecho actual del hombre, habrá que estar a tal declaración.

Relevante es anotar que dada la confusión histórica que el art. 822 contiene, la prueba de que el caso concreto presenta una continuidad en la causa, implicará probar la continuidad en la posesión, pues esta estaría implícita en las causas continuas ${ }^{99}$. Por tanto, acreditar que una servidumbre tiene causa continua, conlleva no solo la existencia de una clase de continuidad sino de dos clases de continuidad. Como sea, ya no estamos en presencia de una discontinua de todas clases.

En tercer lugar, una servidumbre puede ser "continua" o "discontinua" de acuerdo con su visualización, criterio que es recepcionado por el art. 824 del Código Civil para distinguir entre las aparentes e inaparentes. La disposición expresamente señala que es aparente la que está "continuamente a la vista”. Diego San Martín se preocupa de señalar qué se entiende por esta expresión, concluyendo que significa "sin interrupciones; permanen-

${ }^{99}$ Claro Solar (2015), tomo iv, vol. $9^{\circ}, \mathrm{N}^{\circ} 1652$, p. 297; Vodanovic (2016), tomo II, $\mathrm{N}^{\mathrm{O}} 1056$, p. 187. 
temente $\mathrm{o}$, dicho de otra manera, sin pausas" 100 , ideas que compartimos. La circunstancia que el Código sobre la base de este criterio atribuya una denominación específica a las servidumbres (aparentes e inaparentes), en nada afecta su carácter continuo o discontinuo, ya que la denominación no cambia la situación de hecho y, por ende, el resultado, que es lo relevante. Entonces, si la servidumbre está continuamente a la vista, no presenta una discontinuidad de todas clases; si por el contrario no está continuamente a la vista, presenta una discontinuidad de alguna clase.

Desde luego, lo dicho es sin perjuicio de otras posibles clases de continuidad o discontinuidad sobre la base de criterios que no necesariamente ha recogido el Código Civil, pero que podrían ser aplicables.

En Francia, una antigua doctrina seguida por alguna jurisprudencia, sustentó la tesis de que una servidumbre era continua si estaba continuamente a la vista. Ello con la finalidad de ampliar el concepto de "servidumbres continuas" definidas en el art. 688. François Laurent criticaba esta doctrina porque en su concepto la ley no admitiría dos especies de servidumbres discontinuas; solo habría una especie de discontinua, y ella sería la que no se ejerce por sí misma ${ }^{101}$. Su opinión, como el resto de las explicaciones de los autores galos, fue simplemente reproducido en nuestro país ${ }^{102}$, sin siquiera confrontarlo con los propios textos patrios. Es así como se ha bloqueado hasta ahora el desarrollo de una doctrina criolla en la materia.

Pero claro, Laurent escribía a partir del art. 691 del Code el cual, a diferencia del nuestro, no alude a "discontinuas de todas clases". Gracias a esta referencia, en Chile sí es posible distinguir clases de discontinuidad y desechar opiniones como las del citado autor.

En todo caso, debemos aclarar sí, que la continuidad o discontinuidad de los signos externos es un criterio distinto a la causa del gravamen. En ello no tenemos dudas. El punto es relevante porque la doctrina criticada por el maestro de Gante lo que pretendía era sustituir (y por tanto confundir) el criterio del art. 822 (continuidad o discontinuidad según la causa), con el criterio del art. 824 (continuidad o discontinuidad en la vista). Desde esta perspectiva, compartimos el rechazo a esa antigua corriente, porque precisamente no se pueden confundir los criterios ni menos sustituir unos por otros. Al contrario, se puede y deben distinguir muy bien y, en consecuencia, las clases de discontinuidad o continuidad. Ello es necesa-

${ }^{100}$ SAn Martín (1998), p. 80.

${ }^{101}$ Textualmente Laurent, (1873), vol. viII, No 128, p. 160 dice: "la loi n'admet pas deux espèces de servitudes discontinues; il n'y en a qu>une seule, et nous venons de dire que la servitude n'est discontinue que lorsqueelle s'exerce d'elle même".

${ }^{102}$ Claro Solar (1904), p. 189 y Claro Solar (2010), p. 731. 
rio y relevante para la aplicación del art. 882 que, en vez de negar estas distintas clases o especies de discontinuidad, las reconoce para efectos de su regulación.

De todo lo dicho resulta que el inc. $1^{\circ}$ del art. 882 establece, en realidad, como restricción que solo pueden adquirirse en virtud de un título las servidumbres que presenten una discontinuidad de todas clases y las que, presentando alguna clase de continuidad (continuas) ella no sea de vista (inaparentes).

Como hemos señalado en el número anterior de este acápite, podría operar entonces respecto de las citadas servidumbres cualquier modo de adquirir, incluyendo la prescripción adquisitiva, siempre que concurra un título. Sin embargo, al tenor del art. 882 inc. $1^{\circ}$, no siempre es admisible la usucapión. En la materia habrá que distinguir.

Así tenemos que en cuanto a las servidumbres discontinuas de todas clases, quedan comprendidas en estas, todas aquellas respecto de las cuales no concurre siquiera posesión continua, requisito fundamental para la prescripción adquisitiva. De manera que este modo de adquirir no puede ser aplicado de ninguna forma, sea ordinaria o extraordinaria. Podría ser adquirida a través de otro modo de adquirir que exija título, pero no por prescripción adquisitiva. Esta regla, como se puede apreciar, no constituye ninguna excepción a las reglas generales sino que, por el contrario, las confirma.

La idea la ratifica el mismo inc. $1^{\circ}$ del art. 882 al señalar en su parte final que "ni aun el goce inmemorial bastará para constituirlas". Precisamente, "goce inmemorial" no es sinónimo de "posesión inmemorial", sino de "uso inmemorial" 103 . De hecho, es evidente en el punto la diferencia con el art. 691 del $C C$ francés, fuente del art. 882, que alude a "posesión inmemorial". Nuestro Código Civil abandonó correctamente la regla gala, pues, si hay posesión, hay alguna clase de continuidad, la que justamente es de aquellas que dan lugar a la prescripción y, por tanto, a la adquisición de las servidumbres. Claro, si dicha continuidad en la posesión no va unida a la continuidad de vista, será necesaria la concurrencia de un título; si, por el contrario, va unida a la continuidad de vista, no se necesitará de este. Como sea, en ambos casos se podría alcanzar la adquisición por prescripción adquisitiva.

De manera que con razón el art. 882 inc. $1^{\circ}$ dispone que un ejercicio no constitutivo de posesión, por muchos años que transcurran, no configurará jamás la continuidad en la posesión que exige la prescripción adquisitiva. Desde esta perspectiva, es relacionable la norma con el art. 2499 , en cuanto un simple uso que nunca deja de ser mera tolerancia, no confiere posesión alguna (o bien no se prueba que había posesión y no

${ }^{103}$ SAn Martín (1998), p. 189. 
mera tolerancia) ni da fundamento para prescripción alguna.

En cuanto a las servidumbres que presenten continuidad de alguna clase que no sea de vista, la situación es distinta, pues estamos en presencia de aquellas que son continuas por su posesión o por su causa (que conlleva la posesión conforme lo dispuesto en el art. 822). Concurriendo, entonces, continuidad en la posesión, la prescripción adquisitiva sí es posible. Empero, para que esta pueda tener lugar, será necesaria la concurrencia de un título, justo o injusto. Es decir, la excepción que el art. 882 introduce al régimen general de prescripción tiene relación exclusivamente con la exigencia de un título. En particular, constituye una excepción al art. 2510 regla $1^{\text {a }}$. En lo demás, las reglas generales mantienen su vigencia.

Aplicado lo anterior, resulta, entonces, que si en el caso particular hay continuidad en la posesión (por ejemplo, de una servidumbre de tránsito) o, bien, continuidad en la causa, respecto de la cual el Código considera implícita la posesión (por ejemplo, de una de acueducto), es posible la adquisición de las servidumbres a través de la prescripción adquisitiva, pero exhibiendo el poseedor un título. Luego, y dado que tienen plena aplicación las reglas generales, si el título en virtud del cual se adquiere es justo y concurren los demás requisitos legales, podrán adquirirse en cinco años las servidumbres por prescripción ordinaria. Si por el contrario el título es injusto, podrán adquirirse por prescripción extraordinaria.

Por su parte, el inc. $2^{\circ}$ del art. 882 no puede sino leerse siguiendo el discurso iniciado en el primer inciso, de manera que exista armonía entre todas sus partes. De esta manera, debe entenderse que primeramente explicita una regla ya implícita en el inciso primero: si las servidumbres continuas de alguna clase (posesión o causa), pero inaparentes pueden adquirirse en virtud de título, con mayor razón si son continuas de alguna clase y adicionalmente presentan continuidad de vista. Así, las servidumbres continuas de alguna clase y las aparentes, pueden en general ser adquiridas mediante cualquier modo si concurre un título.

Sin embargo, si el modo al que se recurre es en particular la prescripción adquisitiva, la segunda parte del art. 882 inc. $2^{\circ}$ introduce una excepción a sus reglas generales, la cual es constitutiva de la modificación más relevante a estas: las servidumbres continuas de alguna clase, sea de posesión o de causa, y que además sean continuas de vista (aparentes), se pueden adquirir por prescripción de cinco años sin que concurra título alguno. La doctrina tradicional uniforme tiene, por tanto, razón en que esta excepción importa la unificación de los regímenes de prescripción (sin distinguir entre prescripción ordinaria y extraordinaria).

De manera que una servidumbre de tránsito que presente continuidad en su posesión y continuidad en su vista (como cuando hay una senda o una puerta especialmente destinada al tránsito según el art. 824), puede 
adquirirse a través de esta prescripción adquisitiva especial. De igual forma, una servidumbre de acueducto que presenta continuidad en su causa y continuidad en la vista, puede adquirirse a través de esta prescripción adquisitiva especial.

Se observa de lo anterior que, para que tenga aplicación este régimen especial de prescripción, debe presentarse al menos una doble continuidad: continuidad de posesión y continuidad de vista o, bien, continuidad de causa (que llevaría implícita la posesión) y continuidad de vista. En ambos casos operará la prescripción de cinco años, con independencia de si el poseedor exhibe o no un título; $y$, de exhibirlo, con independencia de que sea justo o injusto.

En síntesis, recapitulando la interpretación avanzada en el número anterior en lo que es pertinente, con la corrección que exige el adecuado entendimiento del art. 882 a partir de la frase "discontinuas de todas clases" contenida en su inc. $1^{\mathrm{o}}$, se puede concluir:

- Primero, que de acuerdo con los art. 2498 y 2512 inc. $1^{\circ}$, las servidumbres activas, como derecho real que son, se encuentran sujetas a las reglas generales que rigen la prescripción adquisitiva.

- Segundo, que tales reglas solo dejan de aplicarse o, bien, resultan modificadas, cuando otra disposición expresamente las exceptúa.

252 - Tercero, el art. 2512 no excluye ningún tipo de prescripción adquisitiva para las servidumbres, de modo que en principio son aplicables tanto las reglas de la prescripción ordinaria como extraordinaria a ellas.

- Cuarto, el art. 2512 señala que se excepciona de la manera en que se adquiere por prescripción el dominio (y los demás derechos reales), el derecho de servidumbre, según los términos del art. 882; esto es, según las modificaciones que este artículo hubiese efectuado al régimen general de la prescripción adquisitiva.

- Quinto, el art. 882 establece que las servidumbres discontinuas de todas clases no pueden ser adquiridas ni siquiera por prescripción adquisitiva extraordinaria. Ello porque una discontinuidad total significa que el ejercicio de hecho del contenido de una servidumbre adolece del requisito esencial para que opere el citado modo de adquirir, como es la posesión continua. Aquí no hay sino una ratificación de las reglas generales.

- Sexto, las servidumbres continuas de alguna clase, sea esta por su posesión o por su causa, pero inaparentes (discontinuas visualmente), solo pueden adquirirse en virtud de un título. Siendo solo esta la única excepción, pueden ser adquiridas conforme las reglas generales de la prescripción adquisitiva, ordinaria o extraordinaria, exhibiendo el título exigido. 
- Séptimo, las servidumbres continuas de alguna clase, sea esta posesión continua o causa continua, y aparentes (continuas de vista) concurra o no un título o, bien, este sea justo o injusto, pueden adquirirse por la prescripción adquisitiva única de cinco años. En este caso, la regla especialmente exceptúa al régimen general, al unificar el tiempo de prescripción.

- Finalmente, si se aplican las conclusiones precedentes a las situaciones problemáticas descritas en el acápite II, advertiremos que todas ellas quedan solucionadas, sin perjuicio de cual sea la regla concreta de las descritas que corresponda al caso. Por lo mismo, se eliminan los injustos resultados a los que la doctrina clásica y la interpretación tradicional han llevado, y que hasta hoy no han sido corregidos.

\section{La historia del establecimiento del Código Civil ratifica la interpretación precedente}

En el proyecto de 1847, en el cual aún no se trataban los bienes y, por ende, no existía una disposición equivalente al art. 882, el art. 716 contenía dos incisos relevantes en la materia que tratamos. Por una parte, el inc. $4^{\mathrm{o}}$ señalaba: "las servidumbres inaparentes [...] no se ganan por ninguna especie de prescripción", demostrando desde un principio una animadversión del redactor del Código por la discontinuidad de vista. Lógicamente, porque el propietario no puede reconocerlas e interrumpir la prescripción.

Por otra parte, el inc. $5^{\circ}$ establecía :

"la tolerancia de construcciones permanentes, como la de calzadas o puentes para el tránsito por tierras eriales, pueden solas servir de fundamento a la cuasiposesión i a la prescripción; i la prescripción en este caso es la ordinaria".

Como puede observarse, estamos aquí en presencia de una servidumbre de tránsito, respecto de la cual se admite que su ejercicio de hecho deje de ser una mera tolerancia y se trate de una posesión continua. Ello queda de manifiesto o se presume porque el dueño acepta y soporta obras destinadas al tránsito. Pero además, y en virtud de tales obras, a la continuidad de la posesión se le ha añadido una continuidad en la vista. Y esta doble continuidad, permite efectivamente la adquisición mediante prescripción adquisitiva, que correspondía a la ordinaria que era de diez años entre presentes (hoy cinco años).

El proyecto de 1853 nos presenta los arts. 1022 y 2692, hoy 882 y 2512 , respectivamente. El primero ya establece la restricción a la adquisición de "las servidumbres discontinuas de todas clases" en virtud 
de título, como, asimismo, a las servidumbres "inaparentes". Mientras que la primera referencia no era más que una ratificación de las reglas generales del proyecto de 1847, la inclusión de las "inaparentes" en la exigencia de concurrencia de título significó un cambio conceptual, pues de la regla absoluta conforme a la cual "las servidumbres inaparentes [...] no se ganan por ninguna especie de prescripción”, se pasa a la regla que ello sí es posible, siempre que concurriese un título. Luego, y en armonía con esta nueva situación, el inc. $4^{\mathrm{o}}$ del art. 716 desapareció del proyecto.

Por su parte, el art. 2692 en su regla $3^{\mathrm{a}}$ ya figura que "el derecho de servidumbre se adquiere según el artículo 1022”, disposición que establecía en su inc. $2^{\circ}$ que "las servidumbres continuas i aparentes pueden adquirirse por títulos, o por prescripción de diez años" (hoy cinco años). Si se observa bien, ciertamente el texto admite ya una prescripción única, como se reconoce en la actualidad. Pero en concreto, el plazo introducido era igual al de la prescripción ordinaria de inmuebles entre presentes (diez años). En otras palabras, el art. 1022 inc. $2^{\circ}$ del proyecto de 1853 , no hacía más que reiterar lo señalado por el inciso $5^{\circ}$ del art. 716 del proyecto de 1847: concurriendo la doble continuidad, se adquiere mediante prescripción adquisitiva ordinaria.

Como si no quedase claro, a pesar de ya haberse incorporado el art. 1022 inc. $2^{\circ}$ (hoy art. 882 inc. $2^{\circ}$ ), el proyecto de 1853 en la regla $4^{\text {a }}$ de 254 su art. 2692 (hoy art. 2499), volvió a reproducir el inc. $5^{\circ}$ del art. 716 del proyecto de $1847 \mathrm{y}$, por ende, la citada doble continuidad. Por tanto, en virtud de ambas normas, concurriendo continuidad en la posesión y continuidad en la vista, una servidumbre podía adquirirse por prescripción adquisitiva. El mismo Código señalaba que ello concurría respecto de una de tránsito cuando existieran construcciones permanentes para este.

No extraña, por tanto, que la regla $4^{\mathrm{a}}$ del art. 2692 del proyecto de 1853 finalmente haya desaparecido, como se constata en el proyecto inédito (art. 2682 a.). Sin embargo, debe observarse que su eliminación no es atribuible ahora a un cambio conceptual por parte de Andrés Bello, sino al hecho que resultaba evidentemente redundante con el texto del inc. $2^{\circ}$ del art. 882 (inc. $2^{\circ}$ del art. 1022 del proyecto de 1853), donde la exigencia de la doble continuidad como excepción a las reglas generales de la prescripción adquisitiva ya se había consagrado.

Ratificación de lo señalado es la sustitución de la expresión "cuasiposesión inmemorial" que contenía el art. 1022 del proyecto de 1853 por "goce inmemorial”. Por cierto, impedir la prescripción adquisitiva por existir una "discontinuidad de todas clases", era incompatible con la negación de una adquisición por "cuasiposesión inmemorial". Si había cuasiposesión, significaba que concurría una clase de continuidad (de posesión). Luego, la disposición permitía en su primera parte que concurriendo esta clase de continuidad y, aunque fuese inaparente, se pudiera adquirir una servidum- 
bre por prescripción ordinaria o extraordinaria, exigiendo sí título para ello. De modo que negar en la segunda parte del artículo la adquisición por posesión inmemorial, resultaba absolutamente contradictorio con lo dicho en la primera. La hipótesis que en realidad impedía la adquisición, pero en particular por prescripción adquisitiva, era el uso inmemorial. Este era el caso que se relacionaba con la mera tolerancia. Por tanto, no quedaba más que cambiar la "cuasiposesión" por un término que concordase con la imposibilidad de adquirir servidumbres discontinuas de todas clases.

Ya aprobado el Código, Andrés Bello introdujo al inc. $1^{\circ}$ del art. 882 "continuas" antes de "inaparentes", reafirmando que, aunque concurra en la especie una continuidad de posesión o causa, mientras no esté acompañada de una continuidad de vista, sería necesaria la adquisición en virtud de un título.

En síntesis, los cambios experimentados por las disposiciones proyectadas que precedieron a los arts. 882, 2499 y 2512, en definitiva, lo que persiguieron fue descartar la posibilidad de adquirir por prescripción adquisitiva servidumbres que presentasen una discontinuidad en su posesión, porque faltaría un requisito esencial para ella. Asimismo, limitar la adquisición por prescripción adquisitiva si presentaba una discontinuidad en su vista, pues esto último afectaría la publicidad de la posesión y por ende la defensa del propietario ante el gravamen que se estaba constituyendo.

\section{BiBLIOGRAFÍA}

Alessandri Besa, Arturo (2011). La nulidady la rescisión en el Derecho Civil Chileno. Santiago: Editorial jurídica de Chile.

Amunátegui Perelló, Carlos (2013a). Derecho civil y medio ambiente. Un estudio de la teoría de las inmisiones y su aplicabilidad en el derecho chileno. Santiago: Thomson Reuters.

Amunátegui Perelló, Carlos (2013b). "Origins of the división of servitudes into natural, legal and contractual”. Journal of Civil Law Studies. V. $\mathrm{N}^{\circ}$ 6. Lousiana

Arellano Alarcón, Juan (1949). De la constitución, posesión y prescripción de las servidumbres. Memoria de prueba. Universidad de Concepción. Santiago: Escuela Nacional de Artes Gráficas.

Argudo Périz, José Luis (2013). "Las servidumbres en el código de derecho foral de Aragón", en Ángel Luis Rebolledo (coord.). Tratado de servidumbres. Pamplona: Thomson Reuters Aranzadi.

BaraOna González, Jorge (2012). La nulidad de los actos jurídicos. Bogotá: Grupo Editorial Ibáñez.

BARASI, Lodovico (1947). I diritti reali limitati, in particolare l'usufrutto e le servitù. Milano: Giuffrè. 
Barcia Lehmann, Rodrigo (2008). Lecciones de derecho civil chileno. De los bienes. Santiago: Editorial jurídica de Chile.

Barcia Lehmann, Rodrigo (2010). Código Civil. Doctrina y jurisprudencia. Santiago: PuntoLex S.A.

Barrientos Grandon, Javier (2016). El código civil. Su jurisprudencia e historia. Edición crítica, concordada, comentada y anotada. Santiago: Legalpublishing.

Barrientos Grandon, Javier (2006). "De los bienes y de su dominio, posesión, uso y goce". Revista Chilena de Derecho Privado. N 6. Santiago.

Barros Errázuriz, Alfredo (1930). Cursos de derecho civil. Santiago: Editorial Nascimento.

Bartholus De Saxoferrato (1996). Commentaria. Instituto Giuridico Bartolo da Sassoferrato. Roma: Il Cigno Galileo Galilei Edizione di Arte e Scienza Srl.

Bergel, Jean-Louis (2009), "Servitudes et autres réels spéciaux", in Hugues Périnet-Marquet (dir.). Propositions de l'Association Henri Capitant pour une réforme du droit des biens. Paris: Lexis Nexis

Berguel, Jean-Louis, Marc Bruschi et Sylvie Cimamonti (2000). Traité de droit civil. Les biens. Jacques Ghestin (dir.). Paris: LGDJ.

Biondi, Biondo (1969). Le servitú prediali nel diritto romano. Milano: Giuffrè.

Biondi, Biondo (2002). Las servidumbres. (trad.). José Manuel González Porras. Granada: Comares.

Burdese, Alberto (1998). Manuale di diritto privato. Torino: UTET.

Busto Lago, José Manuel (2013). "Las servidumbres en Galicia en el derecho civil histórico", en Ángel Luis Rebolledo (coord.). Tratado de servidumbres. Pamplona: Thomson Reuters Aranzadi.

Busto Lago, José Manuel (2000). La usucapión de la titularidad de la servidumbre predial de paso. Madrid: Edersa. Disponible en Vlex.

Butera, Antonio (1923). "Delle servitú stabilite per fatto dell'umo", in Contardo Ferrini, Gaetano Pulvirenti y Antonio Butera. Delle servitú prediali. NapoliTorino: Eugenio Marghieri-UTET.

Cerdeira Bravo de Mansilla, Guillermo (2000). Usucapión de servidumbres. Madrid: Marcial Pons.

Cerdeira Bravo de Mansilla, Guillermo (2015). Tratado de servidumbres. Madrid: La Ley.

Claro Solar, Luis (2015). Explicaciones de derecho civil y comparado. Santiago: Editorial Jurídica de Chile.

Claro Solar, Luis (1904). "Ligeras observaciones sobre la continuidad y apariencia en las servidumbres". Revista de Derecho y Jurisprudencia. Año II. N ${ }^{\circ} 1$. Santiago.

Claro Solar, Luis (2010), "Ligeras observaciones sobre la continuidad y apariencia en las servidumbres", en Raúl TAvolari (dir.). Doctrinas esenciales. 
Derecho civil. Bienes. Santiago: Revista de Derecho y Jurisprudencia, edición bicentenario. Puntolex.

Colin, Ambrosio y Henri Capitant (1952). Curso de derecho civil. De los bienes y de los derechos reales principales. (trad.) redacción Revista General de Legislación y Jurisprudencia. Madrid: Instituto Editorial Reus.

Corral Talciani, Hernán (2011). "El ejercicio de la acción de nulidad por un tercero no contratante", en Hernán Corral y otros (coords). Estudios de Derecho Civil. Parte general, Acto Jurídico y Derecho de Bienes. Santiago: LegalPublishing.

Corral Talciani, Hernán (2016). Estudios sobre contratos y obligaciones. Bogotá: Grupo Editorial Ibáñez.

Coviello, Leonardo (1890). "Della usucapione delle servitú prediali nel diritto civile italiano". Rivista italiana per le scienze giuridiche. Vol. x. Roma.

Culaciati, Martín Miguel (2015). “Comentario al art. 2164”, en Marisa Herrero, Gustavo Caramelo y Sebastián Picasso (dirs.), Código civil y comercial de la Nación comentado. Buenos Aires: Infojus.

Chacón, Jacinto (1890). Estudio comparativo del Código Civil chileno. Santiago: Imprenta Nacional.

De la Mata Pizaña, Felipe y Roberto Garzón Jiménez (2014). Bienes y derechos reales. México D.F.: Porrúa.

De La Maza Gazmuri, Íñigo (2016). Código civil. Sistematizado con jurisprudencia. Santiago: Legalpublishing.

Delvincourt, Claude-Étienne (1813). Cours de code Napoléon. Paris: Gueffier.

De Page, Henri (1942). Traité élémentaire de droit civil belge: principes, doctrine, jurisprudence. Bruxelles: Etablissements Emile Bruylant.

D’Ors, Álvaro (2008). Derecho privado romano. Pamplona: Eunsa.

Fabres, José Clemente (1893). Instituciones de derecho civil chileno. Santiago: Imprenta y Librería Ercilla.

Fenet, Pierre-Antoine (1827). Recueil Complet des Travaux Préparatoires du Code Civil. Paris: Au Dépot.

Guzmán Brito, Alejandro (2005). De las donaciones entre vivos: conceptos y tipos. Santiago: LexisNexis.

GuZmán Brito, Alejandro (2013). Derecho privado romano. Santiago: Thomson Reuters.

GuZMán BRito, Alejandro (2006). Las cosas incorporales en la doctrina y en el derecho positivo. Santiago: Editorial Jurídica de Chile.

Grandi (ministro Guardasigilli) (1942). Relazione al Codice Civile del 1942. Disponible en www.consiglionazionaleforense.it/web/cnf/collana-studistorici-e-giuridici/-/asset_publisher/IXdcpIwg0t9M/content/relazione-delministro-guardasigilli-grandi-al-codice-civile-del-1942?largefont. [Fecha de consulta: 5 de agosto de 2017].

Jorquera Carvajal, Manuel (1937). De las servidumbres (titulo XI - libro $2^{\circ} \mathrm{C}$. Civil). Tesis de grado para optar al título de licenciado, Universidad de Chile. Valparaíso: Imprenta Comercial. 
Josserand, Louis (1952). Derecho Civil. (trad.) Santiago Cunchillos y Manterola. Buenos Aires: Bosch.

Jourdain, Patrice (1995). Les biens. Paris: Dalloz.

LACRUZ Berdejo, José Luis (1954). "Usucapión de las servidumbres discontinuas y no aparentes". Revista General de Legislación y Jurisprudencia. Segunda época. Tomo 29. No 5. Madrid. Disponible en vLex: VLEX-282116

Lacruz Berdejo, José Luis y Agustín Luna Serrano (2004). Elementos de derecho civil. Derechos reales. Madrid: Dykinson.

Lasarte, Carlos (2007). Principios de derecho civil. Propiedad y derechos reales de goce. Barcelona: Marcial Pons.

Laurent, François (1873). Principes de droit civil français. Paris: Durand \& Pedone Lauriel. Bruxelles: Bruylant-Christophe \& Comp.

LAUREnt JaCQues, M. (2004). Les servitudes dans la jurisprudence récente de la Cour de cassation. Disponible en www.courdecassation.fr/publications_26/rapport_annuel_36/rapport_2004_173/deuxieme_partie_tudes_documents_176/ tudes_diverses_179/recente_cour_6400.html. [Fecha de consulta: 5 de agosto de 2017].

LÁzaro Guillamón, Carmen (2002). La adquisición de las servidumbres por el transcurso del tiempo. Castelló: Universitat Jaume I.

Lorenzeti, Ricardo Luis (dir.) (2015). Código civily comercial de la nación. Comentado. 258 Buenos Aires: Rubinzal-Culzoni Editores.

Martínez Calcerrada, Luis (1965). "Régimen de adquisición y ejercicio de las servidumbres personales discontinuas (en torno a la usucapibilidad y ejercicio “dinámico" de las mismas)". Revista de Derecho Notarial. N 48. Buenos Aires.

Mazeaud, Henri et Léon, Jean Mazeaud et François Chabas (1994). Leçons de droit civil. Biens. Droit de propriété et ses démembrements. Paris: Montchrestien.

Messineo, Francesco (1949). Le servitù. Milano: Giuffrè.

Peñailillo Arévalo, Daniel (2016). Los bienes. Santiago: Editorial Jurídica de Chile.

PÉrinet-Marquet, Hugues (dir.) (2009). Propositions de l'Association Henri Capitant pour une réforme du droit des biens. Paris: Litec.

Perozzi, Silvio (1893), "Perpetua causa nelle servitù prediali romane". Rivista italiana per le scienze giuridiche. XIV, II-III. Roma.

Pescio Vargas, Victorio (1978). Manual de derecho civil. Santiago: Editorial Jurídica de Chile.

Pescio VARgas, Victorio (1984). Los modos de adquirir el dominio. Valparaíso: EDEVAL.

Planiol, Marcel y Georges Ripert (1946). Tratado práctico de derecho civil francés. (trad.) Mario Díaz Cruz. La Habana: Cultural.

Planiol, Marcel y Georges Ripert (1991). Tratado elemental de derecho civil. Los bienes. (trad.) José Cajica. México D.F.: Cardenas Editor.

Planiol, Marcel y Georges Ripert (1996). Derecho civil. (trad.) Leonel Pereznieto. México D.F.: Ed. Pedagógica Iberoamericana. 
Rebolledo Varela, Ángel Luis (2013). Tratado de servidumbres. Pamplona: Thomson Reuters Aranzadi.

Rodríguez Grez, Pablo (1991). De las posesiones inútiles en la legislación chilena. Santiago: Editorial Jurídica de Chile.

Rodríguez Grez, Pablo (1995). Inexistencia y nulidad en el código civil chileno. Teoría bimembre de la nulidad. Santiago: Editorial Jurídica.

Rosso Elorriaga, Gian Franco (2013). "Destinación del padre de familia en las servidumbres: cuestiones modernas desde el derecho latinoamericano", en Maristela BASSO y otros (eds.). Sistema jurídico romanista y sub-sistema jurídico latinoamericano. Liber discipulorum para el Profesor Sandro Schipani. Bogotá: Universidad de Externado de Colombia.

Rosso Elorriaga, Gian Franco (2014a). "La regla rebus sic stantibus respecto al modus servitutis y sus particulares consecuencias en las servidumbres convencionales", en Carlos Soriano (coord.). Pacta sunt servanda y rebus sic stantibus. Desarrollos actuales y perspectivas históricas. México D.F.: Universidad Panamericana - Editorial Novum.

Rosso Elorriaga, Gian Franco (2014b). "Servidumbres de hecho: su defensa mediante la querella de restablecimiento y su ataque mediante la acción negatoria”, en Álvaro VIDal y otros (coords.). Estudios de Derecho Civil X. Santiago: Legal Publishing.

Rosso Elorriaga, Gian Franco (2016). "Las servidumbres discontinuas pueden adquirirse por destinación del padre de familia. Reinterpretación del art. 881 del Código Civil", en Manuel BarRía (ed.). Estudios de Derecho Civil XI. Santiago: Legal Publishing.

Ruz LÁrtiga, Gonzalo (2014). Explicaciones de derecho civil. Santiago: Legal Publishing.

SACchI, Alessandro (1902), Trattato teorico-pratico sulle servitù prediali. MilanoRoma-Napoli: UTET.

San Martín Devoto, Diego (1998). Las servidumbres. Santiago: Conosur.

Sснмidt Hотт, Claudia (2009). Teoría general de los derechos reales. Comentarios. Santiago: PuntoLex.

Terré, Francois et Philippe Simler (2014). Droit Civil: Les Biens. Paris: Dalloz.

Varas Videla, Eduardo (1925). De las servidumbres. Memoria de prueba. Santiago: Universidad de Chile.

Vera, Robustiano (1894). Código Civil de la República de Chile. Santiago: Gutenberg.

Vial del Río, Víctor (2013). Teoría general del acto jurídico. Santiago: Editorial Jurídica de Chile.

Vial Del Rio, Víctor (2014). La tradición y la prescripción adquisitiva como modo de adquirir el dominio. Santiago: Ediciones UC.

Vodanovic Haklicka, Antonio (2016). Tratado de los derechos reales. Santiago: Ediciones Jurídicas de Santiago. 


\section{Otras obras}

Obras Completas de don Andrés Bello (1887). Proyectos de Código Civil. Vol. XI. Edición hecha bajo la dirección del Consejo De Instrucción Pública. Santiago: Pedro Ramírez.

Obras Completas de don Andrés Bello (1888). Proyecto de Código Civil (1853). Vol. XII. Edición hecha bajo la dirección del Consejo De Instrucción Pública. Santiago: Pedro Ramírez.

Obras Completas de don Andrés Bello (1890). Proyecto inédito de Código Civil. Vol. XIII. Edición hecha bajo la dirección del Consejo De Instrucción Pública. Santiago: Pedro Ramírez.

Obras Completas de don Andrés Bello (1981). Código Civil de la República de Chile tomo I, vol. XIV. Rafael Caldera (dir.). Ministerio de Educación. Caracas: Fundación La Casa de Bello.

Obras Completas de don Andrés Bello (1981). Código Civil de la República de Chile tomo II, vol. Xv. Rafael Caldera (dir.). Ministerio de Educación. Caracas: Fundación La Casa de Bello.

Obras Completas de don Andrés Bello (1981). Código Civil de la República de Chile tomo III, vol. XVI. Rafael Caldera (dir.). Ministerio de Educación. Caracas: Fundación La Casa de Bello.

\section{Jurisprudencia citada}

Aguas del Altiplano S.A. con Dirección de Bienestar Social de la Armada (2012): Corte Suprema, 20 de septiembre de 2012 (casación en el Fondo), Legal Publishing $\mathrm{N}^{\circ} \mathrm{CL} / \mathrm{JUR} / 2068 / 2012$.

Bascuñán con Romero (1906): Corte de Apelaciones de Concepción, 15 de octubre de 1906 (querella de restablecimiento), Revista de Derecho y Jurisprudencia, t. 4, Sec. $2^{\text {a }}$., p. 105; Legal Publishing N CL/JUR/2/1906; vLex No vLex253341606; Raúl Tavolari Oliveros (2010).Jurisprudencias esenciales. Derecho civil. Santiago: Puntolex, 2010.

Colipán Moncada, David con Bucarey Vargas, Ana María (2009): Corte Suprema, 5 de octubre de 2009 (acción de protección), Legal Publishing $\mathrm{N}^{\circ} \mathrm{CL} /$ JUR/1778/2009

Correa Ortega, Teresa de Jesús y María Alicia con Cerda Henríquez, Edgardo (2006): Corte de Apelaciones de Chillán, 12 de octubre de 2006, (recursos de apelación), Legal Publishing $\mathrm{N}^{\circ}$ CL/JUR/3349/2006.

Cuevas G., Patricio y otro con Sociedad Agrícola Super Ltda. (2002): Corte de Apelaciones de San Miguel, 25 de julio de 2002 (recurso de apelación), Microjuris, RDJ7599, MJJ7599.

Moreno Carreño, Cristóbal con Núñez Farías, René (2009): Corte Suprema, 1 de septiembre de 2009 (acción de protección), Legal Publishing N CL/JUR/608/2009 
Pesse Ruiz, Juan Antonio con Molkenbürh, Silvia Ana y Berguer Dempster, Francisco (2010): Corte Suprema, 18 de noviembre de 2010 (acción de protección), Legal Publishing $\mathrm{N}^{\circ} \mathrm{CL} / \mathrm{JUR} / 9704 / 2010$.

P.L., W.R. y Otros con P.B., J.R. y Otros (2015): Corte de Apelaciones de Valparaíso, 14 de enero de 2015 (acción de nulidad), vLex N ${ }^{\circ}$ vLex-553068594.

Romo Pizarro, Osvaldo; González Valencia, Eugenia del Carmen con Herrera Alflatt, María Teresa (2005): Corte de Apelaciones de Valparaíso, 26 de mayo de 2005 (acción de protección), Legal Publishing N CL/JUR/3917/2005.

Ruiz Salgado, Ninette con Kummelin Redlich, Rolf (2005): Corte Suprema, 29 de agosto de 2005 (casación en la forma y en el fondo), Legal Publishing $\mathrm{N}^{\circ} \mathrm{CL} / \mathrm{JUR} / 1028 / 2005$.

Salgado Rojas, Rosalida y Otros con Rojas Zúñiga, Romerindo (2010): Corte Suprema, 25 de enero de 2010 (acción de protección), Legal Publishing $\mathrm{N}^{\circ} \mathrm{CL} /$ JUR/809/2010.

Sociedad Agrícola Super Limitada con Patricio Cuevas Gutiérrez y Eleazar Abarca Olivares (2002): Corte de Apelaciones de San Miguel, 25 de julio de 2002 (querella de amparo), Legal Publishing $\mathrm{N}^{\circ} \mathrm{CL} / \mathrm{JUR} / 2843 / 2002$.

Sucesión Gonzalo Bulnes Aldunate con Agrícola La Obra Limitada (2009): Corte Suprema, 16 de junio de 2009 (casación en la forma y el Fondo), Legal Publishing $\mathrm{N}^{\circ} \mathrm{CL} / \mathrm{JUR} / 3349 / 2006$.

Venegas Inostroza, Olga del Carmen con Cuevas, Graciela del Carmen (2009): Corte Suprema, 3 de septiembre de 2009 (acción de protección), Microjuris, MJJ21164.

Villar Mareiro, Camilo y otra contra Asenjo Silva, Juan Javier y otros (2009): Corte Suprema, 3 de septiembre de 2009 (protección), Legal Publishing $\mathrm{N}^{\circ} \mathrm{CL} / \mathrm{JUR} / 738 / 2009$.

Yunis Ananías, Cesar con Yunis Ananías, Verónica e Hinojosa Bertiolini, Darío (2009): Corte de Apelaciones de Concepción, 16 de octubre de 2009, (recursos de apelación y casación), JurisChile. 